\title{
Technical and conceptual considerations for performing and interpreting functional MRI studies in awake rats
}

\author{
Marcelo Febo , $^{2 *}$ \\ ${ }^{1}$ Department of Psychiatry, The McKnight Brain Institute, University of Florida College of Medicine, Gainesville, FL, USA \\ ${ }^{2}$ Department of Neuroscience, The McKnight Brain Institute, University of Florida College of Medicine, Gainesville, FL, USA
}

Edited by:

Josephine Johns, University of North

Carolina at Chapel Hill, USA

\section{Reviewed by:}

Vincent Daniel Costa, University of Florida, USA

Marc Kaufman, McLean Hospital, USA

\section{*Correspondence:}

Marcelo Febo, Department of

Psychiatry, University of Florida

College of Medicine, P.O. Box 100256,

Gainesville, FL 32610-0256, USA.

e-mail: febo@ufl.edu
Functional neuroimaging studies in rodents have the potential to provide insight into neurodevelopmental and psychiatric conditions. The strength of the technique lies in its non-invasive nature that can permit longitudinal functional studies in the same animal over its adult life. The relatively good spatial and temporal resolution and the ever-growing database on the biological and biophysical basis of the blood oxygen level dependent (BOLD) signal make it a unique technique in preclinical neuroscience research. Our laboratory has used imaging to investigate brain activation in awake rats following cocaine administration and during the presentation of lactation-associated sensory stimuli. Factors that deserve attention when planning functional magnetic resonance imaging studies in rats include technical issues, animal physiology and interpretability of the resulting data. The present review discusses the pros and cons of animal imaging with a particular focus on the technical aspects of studies with awake rats. Overall, the benefits of the technique outweigh its limitations and the rapidly evolving methods will open the way for more laboratories to employ the technique in neuroscience research.

Keywords: fMRI, rats, anesthesia, neural circuits, awake rat imaging, motion artifact, stress, neuroimaging

\section{INTRODUCTION}

For over two decades functional magnetic resonance imaging (fMRI) has been used to investigate human and animal brain function using a variety of experimental paradigms. The most popular functional imaging technique relies on the blood oxygen level dependent (BOLD) contrast mechanism first reported in the anesthetized rat by Ogawa et al. (1990). Rodent fMRI studies have evolved from experiments focused on developing new MR imaging methods to recent work that employs the technique to investigate specific neurobiological mechanisms. A significant advantage of fMRI is that it allows a functional characterization of the awake rodent brain under different treatment and pharmacological conditions (Peeters et al., 2001; Sachdev et al., 2003; Febo et al., 2004b, 2005a,b; Ferris et al., 2005, 2006, 2008; Chin et al., 2006, 2011; Chen et al., 2009; Liang et al., 2011; Zhang et al., 2011). Rather than providing a direct window into neuronal activity, the BOLD fMRI signal depends on the brain's blood supply and cellular oxidative metabolism. However, it supersedes previous in vitro techniques that were used to examine cerebral blood flow (CBF) and glucose utilization in the rat brain using injectable radiolabeled tracers because of its measurement of neural signals in real-time (Porrino et al., 1988; Stein and Fuller, 1992, 1993).

Thanks to a growing number of studies on the nature of the BOLD signal, there is improved knowledge about the relationship between BOLD and neuronal activity (Fox and Raichle, 1986; Fox et al., 1988; Davis et al., 1998; Logothetis et al., 2001; Shmuel et al., 2002, 2006; Kennerley et al., 2005; Tian et al., 2011). The BOLD signal arises from changes in the oxy-to-deoxyhemoglobin ratio in tissue and thus is primarily a hemodynamic signal restricted by the biophysical properties of the local neurovasculature. This should be kept in mind when interpreting neuroimaging data. The use of in vivo single-unit, multi-unit, and local field potential (LFP) recordings and optical imaging methods to investigate changes in neural activity and vascular reactivity at sub-anatomical levels can strengthen the interpretability of fMRI data. We have performed fMRI of the neural actions of cocaine and the lactation stimulus in the unanesthetized maternal rat (Febo et al., 2004b, 2008). The present review will use these studies as methodological examples of fMRI in awake animals. Parallel preclinical and clinical imaging studies can provide a basis for direct translational research that could aid discoveries in different fields of neuropsychiatry. For instance, there have been significant human imaging studies that have investigated the neural actions of cocaine (Breiter et al., 1997; Gollub et al., 1998; Li et al., 2000), whereas there have been a separate series of imaging experiments on human maternal care (Bartels and Zeki, 2004; Nitschke et al., 2004; Strathearn et al., 2008). Collectively, these and other imaging studies have been in partial agreement with several animal studies on the brain regions that are involved in responding to cocaine or infant sensory cues. Animal studies have the design flexibility to verify results with a multiplicity of invasive brain methods that can inform human work and aid in data interpretations. Despite the advantages, there are also challenges to awake animal imaging that are different from those in anesthetized preparations. Several of these have been addressed in past studies (Lahti et al., 1998, 1999; Ludwig et al., 2004; King et al., 2005; Ferris et al., 2008). These include hardware issues (Lahti et al., 1998; Ludwig et al., 2004), animal stress (King et al., 2005), data processing and artifacts (Ferris 
et al., 2005, 2008). This review provides a summary of the methods used for functional MRI experiments in rats with a special focus on awake imaging methods that are used in our laboratory. This includes information on technical and conceptual aspects of fMRI in awake rats, starting with the physiological basis of the BOLD fMRI signal, describing the hardware and methods used to image awake as opposed to anesthetized rats and concluding with a detailed examination of data interpretations.

\section{PHYSIOLOGY OF THE BOLD CONTRAST MECHANISM THE BOLD SIGNAL}

The nuclear magnetic resonance mechanism that provides the basis for generating contrast in MR images depends on the behavior of hydrogen nuclei (protons) in water within the main tissue compartments of the brain. Unpaired protons contain a net positive charge and can act as tiny magnetic dipoles that align along the longitudinal axis ( $z$-axis) of the external magnetic field $\left(\mathrm{B}_{0}\right)$. Protons possess an angular moment $\left(\omega_{0}\right)$, or precession, that is directly proportional to $\mathrm{B}_{0}$ and is described by the Larmor equation $\omega_{0}=\gamma B_{0}$, where $\gamma$ is the gyromagnetic ratio (in the case of $\mathrm{H}^{1} 42.6 \mathrm{MHz} / \mathrm{T}$ ). Precession along the longitudinal $z$-axis is manipulated during typical MR experiments. Combinations of radiofrequency (RF) excitation pulses and switching of magnetic field gradients ultimately result in the recovery of tissue RF signals from different areas of the brain. RF pulses excite protons away from their steady state position imposed by the surrounding $\mathrm{B}_{0}$ field. Relaxation back to the steady state position is governed by two time constants termed $\mathrm{T}_{1}$ and $\mathrm{T}_{2}$. The time constants are associated with the intrinsic properties of specific tissue types (cerebrospinal fluid, white matter, gray matter) and thus allow the generation of contrast through the experimenter-mediated adjustment of echo times (TE) and repetition times (TR). The excitation and relaxation processes result in the emission of RF signals from tissue compartments of the brain. These are detected using coils that localize signals from the tissue of interest (in reality the MR signal is an "echo" of the original relaxation signal). The RF excitation and detection mechanism is accompanied by a series of slice selective, read-out and phase encoding gradient variations that allow the encoding of brain spatial information.

A variant of $\mathrm{T}_{2}$, known as $\mathrm{T}_{2}^{*}$ ("T-2-star"), is produced by inhomogeneities in the magnetic field that cause reductions in $\mathrm{T}_{2}$ (faster transverse relaxation rate). Deoxyhemoglobin ( $\mathrm{dHb}$ ) in plasma red blood cells (RBCs) is paramagnetic while oxyhemoglobin $\left(\mathrm{HbO}_{2}\right)$ is diamagnetic (Pauling and Coryell, 1936) and the intravascular difference between the two provides for an endogenous contrast mechanism (Ogawa et al., 1990). Ogawa et al. (1990) provided evidence that a decreased $\mathrm{T}_{2}^{*}$ signal in blood vessels, particularly veins of the rat cortex, is due to blood oxygenation state. Darker veins in the cortex were distinguishable in rats inhaling low $\mathrm{O}_{2}$ concentrations in inspired air (more $\mathrm{dHb}$ ) while increased $\mathrm{O}_{2}$ saturation (significantly less $\mathrm{dHb}$ ) increased the brightness of images. The $\mathrm{T}_{2}^{*}$ contrast was observed to be dependent on blood oxygenation. Therefore the BOLD signal arises from changes in the tissue concentrations of $\mathrm{dHb}$. Seminal publications followed that provided support for task-dependent changes in the BOLD signal that occurs in $\mathrm{T}_{2}^{*}$ weighted images of the human somatosensory, motor and visual cortices (Bandettini et al., 1992; Ogawa et al., 1992).

\section{RELATION BETWEEN CEREBRAL HEMODYNAMICS AND NEURONAL ACTIVITY}

Oxidative and non-oxidative metabolism supports neurons and glial cells (Kasischke et al., 2004). Elevations in arterial blood flow supply glucose and $\mathrm{O}_{2}$, which serve as fuel to generate the cellular energy substrates ATP and lactate. Most of the neuronal ATP expenditure is used to restore the equilibrium of the electrochemical potential for $\mathrm{Na}^{+}, \mathrm{K}^{+}$and $\mathrm{Ca}^{2+}$ at synapses (Attwell and Iadecola, 2002). During conditions of high neuronal and metabolic activity, $\mathrm{O}_{2}$ diffuses down a steep concentration gradient from plasma RBCs across the capillary walls into the surrounding parenchymal tissue. This leads to $\mathrm{dHb}$ accumulation in the venous compartment. The paramagnetic effect of $\mathrm{dHb}$ is "felt" by local water protons in the intra and extravascular compartments, and this increases the relaxation rate of protons, decreasing the signal intensity in $\mathrm{T}_{2}^{*}$ weighted $\mathrm{MR}$ images. This is a transient effect, however, as the BOLD signal increases (increased $\mathrm{T}_{2}^{*}$ ) within a few seconds of stimulus delivery. The supply of oxygenated blood is associated with increased delivery to metabolically active regions of the brain. Fractional increases in plasma $\mathrm{HbO}_{2}$ saturation from baseline levels therefore increase the $\mathrm{T}_{2}^{*}$ signal. Indeed, visual and somatosensory evoked changes in $\mathrm{O}_{2}$ metabolism was estimated to be $5 \%$ above baseline levels, but there is nearly a 30 $50 \%$ increase in blood flow to the active cortical regions (Fox and Raichle, 1986; Fox et al., 1988). Therefore, increased CBF is several orders of magnitude above the $\mathrm{O}_{2}$ demand of the tissue. The over-compensatory mechanism is instrumental in generating the BOLD response observed in many studies.

There have been thorough investigations of the possible neurovascular mechanisms contributing to the BOLD signal as well as the relation between the BOLD signal and neuronal activity. Knowledge from these studies contributes to the understanding of fMRI data. Stimulus-dependent increases in $\mathrm{O}_{2}$ consumption in the rat brain are associated with presynaptic action potential firing and ATPase-dependent movement of ions against their electrochemical gradients across the cell membrane (Attwell and Iadecola, 2002). Techniques to measure microscopic changes in tissue oxygenation and perfusion have been instrumental in understanding the underlying dynamics of the BOLD signal. Using intrinsic optical imaging and laser Doppler flowmetry, Malonek and Grinvald (1996) investigated the dynamics of the hemodynamic response in the cat visual cortex. It was shown that an increase in $\mathrm{HbO}_{2}$ and $\mathrm{CBF}$ response near single cortical columns occurs within several seconds (2-3 s) of visual stimulus presentation (Malonek and Grinvald, 1996; Malonek et al., 1997). At the single neuron level, it appears that there is an initial decrease in tissue $\mathrm{O}_{2}$ content due to a greater oxygen extraction fraction immediately after increasing firing activity (Thompson et al., 2003). This is followed by increases in $\mathrm{O}_{2}$ that may be due to the elevated CBF (Thompson et al., 2003). Simultaneous fMRI and neurophysiological recordings taken from the anesthetized rhesus macacque's visual cortex demonstrated a near linear relation between BOLD and LFP, but this may not be the case for single-unit activity (Logothetis et al., 2001). The closer correspondence between BOLD and LFP's may be helpful in understanding the "type" of neural processing and "computational level" contributing the most to fMRI results. Estimates of the primate cortex indicate that each $1 \mathrm{~mm}^{3}$ (which is about the size of a single volume element or 
"voxel" in human studies) contains approximately 50,000 neurons (Douglas et al., 2004). LFPs reflect larger scale electrical activity as a result of the cooperative interactions between populations of perhaps thousands of neurons rather than spike input or output at the single neuron level (Nadasdy et al., 1998). This is perhaps one of the most critical aspects of neural processing that should be carefully considered when interpreting BOLD data.

To sum, the above data describe biological correlates of the mechanisms involved in generating the BOLD responses observed in fMRI studies. It appears, at the microscopic level (measured by intrinsic optical techniques), that there is evidence of a tight coupling between single neuron activity and oxygen metabolism that contributes to generating the BOLD signal, but larger scale electrical oscillations at a macroscopic level may contribute to a larger extent. Regardless the specific neural mechanism, the steps between neuronal activity and BOLD involves coupling cellular metabolism and cerebrovascular reactivity (Davis et al., 1998; Lee et al., 2001; Sheth et al., 2004). fMRI signals are ultimately an indirect reflection of neural activity that cannot offer details on specific neuronal firing patterns as measured by electrophysiological techniques (Buzsaki et al., 2007; Logothetis, 2008). On the other hand, the measurement and mapping of neural signals over extended regions of the rat brain is unmatched by these techniques.

\section{HARDWARE}

\section{MR SCANNER}

The high field MR scanner produces the external $\mathrm{B}_{0}$ field and contains the spatial encoding gradient coils that are oriented along the longitudinal $z$ and transverse $x-y$ axes. The use of 4.7 and $7 \mathrm{~T}$ horizontal bore systems for rodent applications have been optimal both because of the high signal-to-noise ratio (SNR) and good $\mathrm{T}_{2} / \mathrm{T}_{2}^{*}$ contrast for functional studies. Scanners with high quality spatial encoding gradients, automated shimming (for correcting small field variations around the brain), and pre-installed pulse sequence routines that run on user-friendly console software are of choice for many applications-driven laboratories. At higher fields it is possible to obtain an in-plane voxel resolution for functional scans of about $390-469 \mu \mathrm{m}^{2}$ with $12-20$ coronal slices $(1-1.2 \mathrm{~mm}$ slice thickness). This covers most of the rat brain from the olfactory bulb to the cerebellum using $\mathrm{T}_{2}$ weighted fast spin echo (FSE) sequences with minimal anatomical distortions (Figure 1). For localized rat brain studies with fewer slices, focusing on the coordinated activity of a few subsets of areas, the in-plane resolution can be increased to $100-250 \mu \mathrm{m}^{2}$. An advantage of having higher resolution images is that they can create voxels that better localize activity in the cortex (see columnar level resolution studies in Kim et al., 2000). However, the smaller voxel size results in lower SNR especially at lower field strengths.

Many fMRI studies have been performed using gradient echo echo planar imaging (GE EPI) because of its greater sensitivity to magnetic susceptibility and the BOLD effect. Gradient echo sequences use rapidly changing MR gradients to excite protons into the transverse plane (rather than using RF pulses). However, because of the same susceptibility effects, the GE EPI is highly vulnerable to signal loss at air-tissue interfaces in the temporal and paranasal regions. This leads to loss of data in important

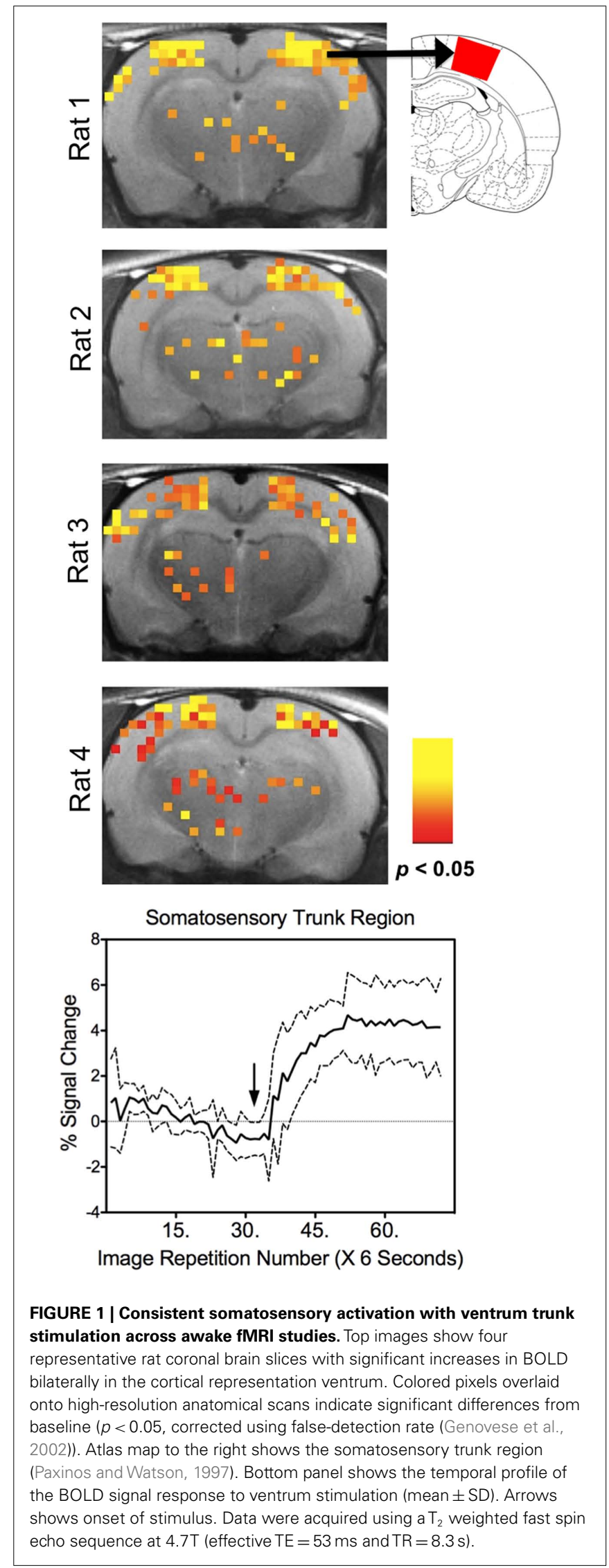


areas such as the ventral hippocampus, amygdala, and medial prefrontal cortex (Febo et al., 2004b; Ludwig et al., 2004). GE EPI has a high sensitivity to physiological noise and shows anatomical distortions (spatial warping) that can produce alignment and registration errors. Most modern MR console software contains built-in algorithms that correct these distortions. However, to correct the spatial warping, additional scan time must be added to acquire field maps that aid in unwarping reconstructed images. Finally, GE EPI sequences are more sensitive to intravascular and extravascular large vein signals that are distant from the actual foci of activity (Duong et al., 2003). Spin echo EPI (SE EPI) at high fields are more sensitive to intra and extravascular compartments closer to the capillaries and therefore are commonly used for fMRI studies at higher field strengths (Duong et al., 2003).

At high fields, $\mathrm{T}_{2}$ weighted spin echo sequences appear to suffer less from the aforementioned issues (Duong et al., 2003; Goense and Logothetis, 2006; Poser and Norris, 2007; Ye et al., 2011). Single shot spin echo sequences (SE EPI) and multi-segmented $\mathrm{T}_{2}$ weighted FSE can be used successfully with rats. The latter has been the sequence of choice for many of our experiments in awake rats. There is support in the literature for the use of FSE and SE EPI sequences for BOLD imaging (Duong et al., 2003; Goense and Logothetis, 2006; Poser and Norris, 2007; Ye et al., 2011). Figure 1 illustrates the results from a study of the rat somatosensory cortex (Febo et al., 2008). In the study, awake female rats were stimulated on the ventrum skin while being imaged at $4.7 \mathrm{~T}$ using a $\mathrm{T}_{2}$ weighted FSE sequence ( $\mathrm{TR}=8 \mathrm{~s}$ and $\mathrm{TE}=53 \mathrm{~ms}$ ). We observed increased BOLD signal intensity in areas that correspond to the trunk region of the primary somatosensory cortex (Figure 1). This was observed in all the tested animals. Temporal profiles of the BOLD signal are shown for seven individual rats just to give an idea of the variability between subjects. Figure 2 further supports the notion that $\mathrm{T}_{2}$ FSE sequences provide BOLD weighting. Awake rats were provided with $5 \% \mathrm{CO}_{2}$ in inspired air during functional scanning. A rise in signal intensity is observed

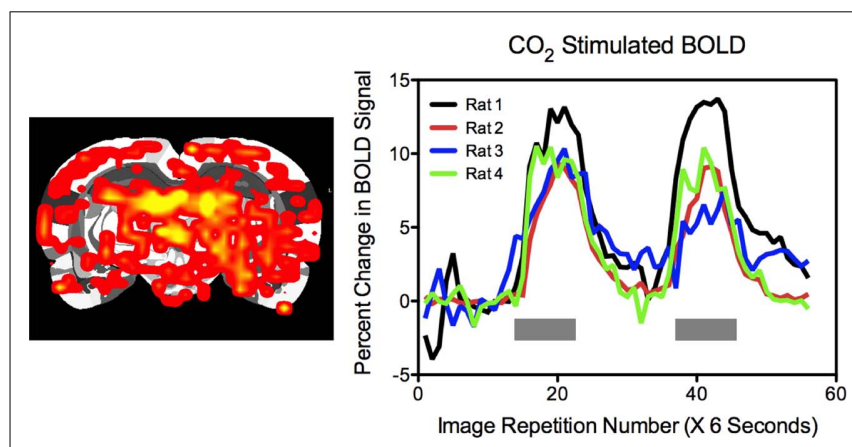

FIGURE 2 | Vascular reactivity contributes to BOLD signal changes. The figure illustrates how hypercapnic conditions can elevate the BOLD signal in the absence of any neural stimulus. The activation map on the left shows dramatic increases in BOLD with $5 \% \mathrm{CO}_{2}$ inhalation during functional image acquisition. Plot on the right shows the timecourse of BOLD signal intensity changes over the course of the scanning. Plots are shown for four individual rats, each showing a similar pattern of BOLD signal change. The gray bars below indicate the interleaved epochs of normocapnia and $\mathrm{CO}_{2}$ exposure. Data were acquired using a $T_{2}$ weighted fast spin echo sequence at $4.7 \mathrm{~T}$ (effective $\mathrm{TE}=53 \mathrm{~ms}$ and $\mathrm{TR}=8.3 \mathrm{~s}$ ). at the specific times in which animals are exposed to hypercapnia. Switching back to normocapnic conditions results in a return to baseline signal intensity. This global cerebrovascular reactivity is due to changes in CBF in the absence of alterations in neuronal activity. These two studies indicate that BOLD signal changes may be of neural (Figure 1) and also of vascular origin (Figure 2).

\section{RF COILS AND ACCESSORY EOUIPMENT}

Studies of the rat brain using MR scanners require the use of RF coils that serve as the source of the $B_{1}$ field (the 90 and 180 degree pulses) that excite water protons in tissue to the transverse planes. The RF coils also serve to detect longitudinal and transverse signal relaxation. There are varieties of coils that are used for neuro-applications. Many laboratories construct their own RF coils (Ugurbil et al., 2003; Doty et al., 2007). These are usually single copper wire loop tuned to the magnet frequency $(4.7-7 \mathrm{~T}$ or $200-300 \mathrm{MHz}$ range, respectively). The coil is aligned over the area of interest, such as over the head overlying the cortex. The loop coil configuration, however, has less spatial coverage and usually results in signal drop from dorsal to ventral areas of the brain that makes this type of configuration less favorable for developmental studies. The configuration prohibits coverage of signals from brain structures such as the hypothalamus and midbrain that are farthest in distance from the coil. This can be overcome by using a dual RF coil system built into an MR compatible restrainer of the head and body (Ludwig et al., 2004), or a quadrature coil system with improved $B_{1}$ coverage of the brain (EkamImaging Inc., Shrewsbury, MA, USA; Figure 3).

In addition to the main electronics that are needed to run functional brain scanning in rats there are also other useful accessory devices. For anesthetized preps, beds with integrated head and/or body holders are important to place animals correctly inside the bore of the magnet. Typically these are necessary to align animals correctly within the isocenter of the MR spectrometer prior to image acquisition. Physiological monitoring devices are also an essential part of the animal imaging setup. This includes MR compatible temperature probes, pulse oximeters, capnometers, electroencephalographic (EEG) and electromyographic (EMG) recorders, respiratory pillows and transducers, and other devices according to the needs of the investigator. The physiological measures are used to "gate" the image acquisitions to remove respiratory and cardiac pulsations that can appears as low frequency artifacts (Purdon and Weisskoff, 1998; Peeters and Van Der Linden, 2002; Bhattacharyya and Lowe, 2004). Stimulation devices may be needed when evoking sensory responses, such as for whisker and forepaw stimulations. The stimuli for sensory evoked responses can be timed to the functional image acquisitions for accurate correlations with BOLD signal responses during block design studies.

\section{ANIMAL EXPERIMENTAL PREPARATIONS ANESTHETIZED PREPARATION}

Anesthetized preparations are used extensively for fMRI studies in rats. The methods used generally are not suitable for longitudinal studies in the same population of animals. In many applications 

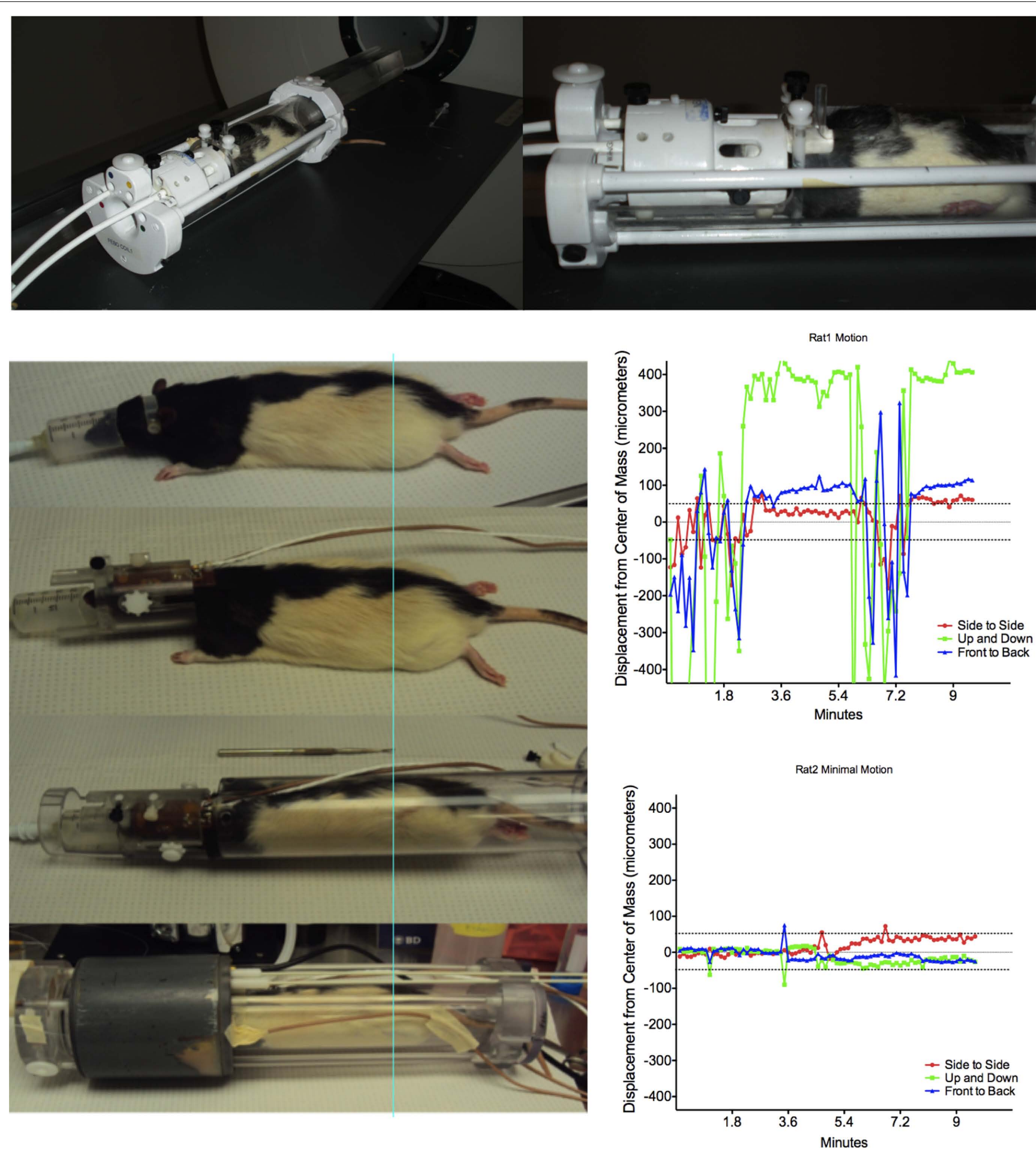

FIGURE 3 | Awake animal setup used in our studies. Top images show a quadrature radiofrequency coil system. Images on the left show (from top-to-bottom) step-by-step procedures for setup in the rat dual coil system. Figure on the right illustrates animal movement

the femoral artery of the rat is catheterized to allow the sampling of arterial blood gases and a close monitoring of arterial blood pressure and $\mathrm{pH}$ during scanning. Changes in the partial during functional scanning. Shown are plots of displacement in $\mathrm{mm}$ from the center of mass. Note that the most dramatic movements are in the $y$-axis (up and down) direction. Newer coil designs minimize this form of movement.

pressures of blood gases may be indicative of alterations of basal conditions that can alter the magnitude of the BOLD signal. This is important since hypoxia and hypercapnia modulate baseline 
BOLD signal in the rat, perhaps independently of basal neural activity and metabolism (Bandettini and Wong, 1997; Cohen et al., 2002). Figure 2 shows an example of this. Controlling for movement is also important and some laboratories use chemical agents that can suppress muscle contractility during scanning. Marota et al. (2000) used the paralyzing agent pancuronium to eliminate unwanted respiratory pulsations in the anesthetized rat. Others have used the muscle relaxant gallamine to paralyze animals during MR scanning (Xi et al., 2004). The animals in the cited studies were tracheostomized and mechanically ventilated during experiments (Marota et al., 2000). The experimenter-controlled activity facilitates "gating" procedures to remove artifacts without significant spontaneous variations in breathing rate. From a strict engineering approach, this rigorous methodology is ideal given the tenuous quality of the BOLD signal. Despite some of these advantages, however, the invasive procedure precludes long-term developmental studies in rats. Alternatively, arterial blood pressure and respiration rates can be measured non-invasively using a pulse oximetry over the tail of the rat and a respiratory pillow placed just underneath the animals' chest.

\section{AWAKE SETUP}

Our laboratory has utilized methods to image awake rats as an alternative to imaging under anesthesia. Before this is done, however, animals must be acclimated to the restraint conditions and MR pulse sequence noise. The procedures for acclimation are carried out for 5 days prior to collection of imaging data. Both acclimation and actual imaging experimental setup procedures are done under similar conditions. Rats are first anesthetized under $2-4 \%$ isoflurane gas to enable placement into a head restrainer (Figure 3). There is evidence that isoflurane anesthetized animals regain motor function and coordination within minutes (Eger and Johnson, 1987), and thus, volatile anesthetics such as isoflurane are useful when quick setup and awakening are desired. An important part of the restraint setup are the ear bars that allow the proper orientation of the head (Figure 3). A semi-circular plastic headpiece containing blunted ear bars are first placed over the animal's head and fitted into the ear canals. These are non-invasive (requiring no surgery) and are not made of abrasive or harmful material. Their placement is the same as standard stereotaxic ear bars. Other laboratories have taken another approach, that is, to bolt or permanently affix the holders to the skull of the animals to ensure that the animals will not be able to move during scanning (Miller et al., 2003; Sachdev et al., 2003; Desai et al., 2011). We have not found that this approach is necessary. The animal is then guided through the center of the coil/head holder unit and the incisors placed over a bite bar. A plastic latch locks down over the nose with a screw. The lateral ear bars contain outer grooves that accommodate lateral screws that are used to align the animal in the holder and fix its position in the restrainer. The body is placed into a tube that has shoulder bars and an overlying square plastic peg that prevents upand-down movement during scanning. The entire system is placed into a chassis that fits the bore of the magnet and can be fastened inside of it. In the experience of the author, the setup time is quite short ( $\sim 10 \mathrm{~min})$. The system has plenty of room to accommodate accessory equipment for stimulus delivery or physiological monitoring (see above). The above system allows the rodent to remain in a semi-crouched position while being scanned (forelimb movement is more restricted). Figure 3 shows movement along the $z$ and $x-y$ directions inside the scanner. As may be observed, most movement comes from the $y$ direction (up and down movements). The rats seldom move in the back-and-forth $(z)$ and side-to-side $(x)$ if positioned correctly. The design of the newer coil system used in our laboratory (Febo and Pira, 2011) minimizes the $y$ direction movement. Other groups have used positioning screws that are affixed to the skull and have obtained good results. For example, Desai et al. (2011) carried out fMRI-optogenetic experiments in awake restrained mice. The mice had miniature plastic screws affixed to the skull. They used a short (3-day) acclimatization period and provided animals with "treats" after restraint sessions. It is possible that both approaches will yield good results, and perhaps using cranial fixtures to prevent movement may be preferable for methods that include additional invasive procedures during fMRI scanning.

\section{POTENTIAL EFFECTS OF ANESTHETICS AND RESTRAINT STRESS \\ EFFECTS OF ANESTHETICS ON BASAL NEURONAL FIRING}

Motion must be minimize during MR scanning (Figure 3). Both gross movements (for example, slow shifts in head position, sustained or transient leg motion, chewing, vocalizations) and physiological motion (pulsations due to cardiac and respiratory cycles) can significantly degrade multi-repetitions MR scans. It can also contribute to false activation patterns that correlate motion with stimulus presentations (Freire and Mangin, 2001). In our laboratory, we prescreen and process data for motion artifact and signal drift that may arise from different sources. Images with minor artifacts are realigned using in house software or Statistical Parametric Mapping software (SPM8; http://www.fil.ion.ucl.ac.uk/spm/). Of course, anesthetizing animals during scanning also minimizes motion artifacts but this reduces the magnitude of the BOLD signal in the rat brain (Lahti et al., 1999; Peeters et al., 2001).

There are significant lines of evidence suggesting that agents typically used for anesthetizing animals can suppress certain forms of neuronal activity and modify specific patterns of neuronal activity and metabolism. For instance, there are differences in basal and stimulated brain glucose utilization (cerebral metabolic rate for glucose, or, $\mathrm{CMR}_{\mathrm{glu}}$ ) and $\mathrm{CBF}$ in awake vs. anesthetized rats (Nakao et al., 2001). Stimulation of the whisker-to-barrel cortex pathway resulted in differential $\mathrm{CBF}$ and $\mathrm{CMR}_{\text {glu }}$ across regions when rats were anesthetized with halothane (Nakao et al., 2001). The results of the latter study suggest that although the barrel cortex is active in the anesthetized state, other regions along the pathway arising from the stimulation of peripheral sensory receptors are suppressed and may thus require a conscious state (Nakao et al., 2001). Evoked potentials in the barrel field cortex have been shown to vary between anesthetic conditions (Martin et al., 2006). The amplitudes of field potential responses to graded levels of repetitive electrical stimulation to the whisker pads are reduced to a greater degree in anesthetized vs. awake rats (Martin et al., 2006). Firing of action potentials over localized regions of the awake rat visual cortex showed higher frequencies and bursting but lower pair-wise correlations between single units 
than ketamine-anesthetized rats (Greenberg et al., 2008), suggesting that the propagation of actions potential in localized networks is modified by the induction of an anesthetized state. Halothane, isoflurane, and desflurane can differentially affect gamma band oscillations in the rat cortex (Imas et al., 2004, 2005). This is important because field potential activity is believed to correlate well with BOLD signal changes. Graded levels of isoflurane (1.8$2.2 \%$ ) also suppress EEG bursts measured in the primary sensory cortical area representing the forelimb of the rat and also reduced spontaneous variations in CBF (Liu et al., 2011). These levels of isoflurane are within the range that causes suppression of bursting in sensory cortical EEG patterns (Hartikainen et al., 1995). Research on the role of anesthetic agents in modulating neuronal activity raises concerns about the use of deep levels of anesthesia for rat brain imaging experiments (Austin et al., 2005; Masamoto et al., 2009; Angenstein et al., 2011). Variations in the pattern and magnitude of neuronal activity will vary according to anesthesia type and concentration. This underscores the importance of parsimony when interpreting data from studies with anesthetized animals. It is impossible to infer the animal's baseline state and unwarranted to assume that functionally interconnected regions respond similarly in awake and anesthetized conditions (Nakao et al., 2001).

\section{EFFECTS OF ANESTHETICS ON CEREBRAL HEMODYNAMICS}

In addition to the cited neural actions, anesthesia can influence global cerebrovascular reactivity. The choice of anesthetic and calibration of the depth of anesthesia are therefore important. The effects of volatile anesthetics on the BOLD signal, CBF, and CBV have been investigated. Hypercapnia-induced BOLD signal changes, which occur in the absence of neuronal activity, are of much greater magnitude in awake rats (Brevard et al., 2003). This suggests that cerebrovascular reactivity is affected by anesthesia. It is also important to note that basal levels of $\mathrm{O}_{2}$ metabolism and neuronal spiking frequency in the cortex are reduced by deep levels of alpha-chloralose (Hyder et al., 2002). The results of the latter study provide evidence that basal conditions might be associated with the magnitude BOLD signal changes. Larger magnitude changes in BOLD may reflect lower basal firing of neurons in animals that are deeply anesthetized whereas lighter levels of anesthesia allow for smaller magnitude changes in BOLD in the face of higher basal activity (Hyder et al., 2002). Thus, the absence of neuronal recording methods or imaging methods to assess CBF may lead to incorrect interpretation of the magnitude of the BOLD signal.

Basal CBF levels in 2\% isoflurane anesthetized rats were observed to be greater than in the awake state (Sicard et al., 2003). Isoflurane anesthesia can act as a vasodilating agent that increases blood flow. The percent change in CBF and BOLD in response to $\mathrm{CO}_{2}$, however, is lower in anesthetized rats (Sicard et al., 2003). The lower magnitude response could be due to higher basal levels of blood flow (Sicard et al., 2003). Thus, in isoflurane anesthetized animals there seems to be direct modulation of CBF that is independent of the effects on neuronal activity (Masamoto et al., 2009). Isoflurane reportedly increases CBF globally due to its vasodilating actions (Liu et al., 2011). Spontaneous CBF changes are suppressed by increasing levels of isoflurane from 1.8 to $2.2 \%$
(Liu et al., 2011). Thus, light sedation with isoflurane $(<1.8 \%$ in inspired air) might minimize the above-described effects. It has also been reported that alpha-chloralose specific parameters for forepaw stimulated BOLD activity in the somatosensory cortex do not work under isoflurane anesthesia (Masamoto et al., 2009). The accumulating evidence underscores the importance of considering the effects of anesthetics on both neuronal activity and cerebrovascular reactivity when designing fMRI studies and interpreting the data.

Finally, a fundamental concern of anesthetized preparations is that, as a preference of choice or perhaps based in published data, different laboratories vary their use of specific types of anesthetic agents. These include volatile anesthetics, such as isoflurane, desflurane, halothane, urethane, and injectable agents, such as medetomidine, ketamine, alpha-chloralose, and others. There is growing evidence that the different agents may have varying effects on BOLD signal and neuronal activity, and this could potentially lead to variations in findings between laboratories. Austin et al. (2005) compared the effects of halothane levels and alpha-chloralose on cortical stimulation evoked BOLD activity and found that the amplitude responses with varying levels of halothane were unchanged, whereas deepening anesthesia levels with alpha-chloralose lead to greater amplitude evoked responses (Austin et al., 2005). Indeed, a similar finding is reported by Masamoto et al. (2009), however, the latter study seems to show greater variability in peak CBF and summed field potential responses with alpha-chloralose than with isoflurane (Masamoto et al., 2009). BOLD functional connectivity (FC) analysis during resting state is also hindered by variations of the type of anesthetic chemical used. Medetomidine anesthesia allows betterlocalized correlations between seed voxel regions (higher specificity of correlated regions) and isoflurane has the opposite effect on FC analysis (Williams et al., 2011). It appears that FC analysis works optimally under isoflurane with concentrations in the range of $0.5-1.0 \%$ but fails at higher levels (2.9\%; Wang et al., 2011). Frequency-dependent changes in amplitude BOLD and field potential responses to forepaw stimulation were observed over a wider range of stimulation frequencies under urethane (1-15 Hz) than under alpha-chloralose $(1-3 \mathrm{~Hz}$; Huttunen et al., 2008). Therefore, two laboratories implementing different types of anesthetics, say urethane in one and alpha-chloralose in the other, may result in disparate results. There are no optimal anesthetic types that can be used that will produce entirely reproducible findings across laboratories that carry out discovery-oriented research. The development of the technique, given the above-summarized data, should be to employ the technique in awake conditions wherever possible.

\section{RESTRAINT STRESS}

Stress is one of the biggest factors that present challenges to designing and interpreting fMRI data in awake animals. One of the concerns of acclimation is that it may produce chronic stress exposure to the animals. Is the type of restraint used for imaging equivalent to the form of restraint used in studies investigating the chronic effects of immobilization stress? The latter usually uses a wire mesh that restricts total movement while the imaging setup only involves restraint of the head while the limbs 
and torso are not restrained. Thus, the imaging setup seems to involve intermittent stress that may have transient and not chronic effects. Do any residual chronic stress effects during acclimation have a permanent impact on brain physiology and behavior? This question really attends to the permanent changes that have been reported using other chronic stress models such as the social defeat stress model (Tornatzky and Miczek, 1993) that may result in animal groups that are in an overall depressed state or a state of behavioral despair (Krishnan and Nestler, 2008). Whether or not stress is present in restraint-acclimated rats is not a matter of debate. The aim is to determine whether the effects of stress are at tolerable levels.

King et al. (2005) reported that various physiological variables (e.g., respiratory rates, blood pressure, corticosterone levels) of Sprague-Dawley rats are reduced following 5-8 days of restraint. Most measures are reduced near to pre-stress baseline levels on day 4-5. An important outcome however was that there was a significant increase in contrast to noise while no changes in basal CBF values were noted. This could signify that the lower gross movement and physiological rhythms improve image quality. At the same time it points to the brains autoregulatory capacity in awake rats that remains intact regardless of whether or not they are acclimated (King et al., 2005). The data are consistent with reports indicating that rats habituate to repeated daily $1-2 \mathrm{~h}$ restraint for 4-9 days (Melia et al., 1994; Dhabhar et al., 1997). Rats show normal patterns of food intake and heart rate following habituation to restraint (Haleem, 1996; Stamp and Herbert, 2001). Importantly, habituation to repeated daily sessions of restraint is not necessarily indicative of impaired hypothalamic-pituitary-adrenal (HPA) axis function, since rats acclimated to restraint stress still show increased c-fos activation and corticosterone levels to a novel stressor (Melia et al., 1994). Recent unpublished work from my laboratory provides evidence that $22 \mathrm{kHz}$ ultrasonic "distress" calls are reduced by day 4 and 5 of acclimatization in comparison to day 1 (Figure 4, unpublished results by Michael Reed and Marcelo Febo). At the same time struggle movements diminish in these animals when tested on a forced swim assay (Figure 4). One interpretation might be that animals are in a state of behavioral despair and are therefore not struggling. However, when viewed collectively the tests point to signs of physical and behavioral adaptations to the restraint conditions. The results support less struggle movements reported previously in Sprague-Dawley rats (King et al., 2005). Therefore rats seem to be fully capable of adapting to the head restraint conditions.

A central question is whether animals adapt to stress and is this adaptation indicative of learning or an overall impairment of the HPA axis and a resultant depressed behavioral state. There is partial support in the literature against the latter assertions. Parry and Mcelligott (1993) devised a method for head immobilization in awake rats in order to study central regulation of cardiovascular function. They reported that side-by-side acclimatization of rats to restraint reduced the stress of individual animals that are being acclimated. We have used a similar acclimatization procedure in our studies in which groups of animals are simultaneously exposed to daily sessions of restraint. Heart rate and blood pressure normalized after initial exposure to restraint indicating that the procedure was minimally stressful (Parry and Mcelligott, 1993). Barnum et al. (2007) investigated the hyperthermia effects of chronic restraint stress and compared these to other forms of stress such as the social defeat model and isolated cage confinement (Barnum et al., 2007). They observed that corticosterone and stress-induced hyperthermic responses to restraint stress adapted after 5-6 days of repeated exposure. However, this was not observed for the social defeat stress model indicating that the two forms of stress have different outcomes. There have been reports of the differential reactivity of the HPA axis to stress and immunological challenge across various strains of rats. Our initial experiments were all in Sprague-Dawley (SD) rats while the more recent work is performed in Long Evans. Dhabhar et al. (1997) investigated the chronic effects of stress on adaptation of the HPA axis in SD, Lewis and F344 rats (Dhabhar et al., 1997). SD and Lewis rats showed adaptations over the course of the 4-h immobilization stress paradigm as well as during the 10-day chronic regime of stress whereas F344 rats did not in either case (Dhabhar et al., 1997). Despite the reported evidence of adaptations to stress, there are important long-term effects that should not be
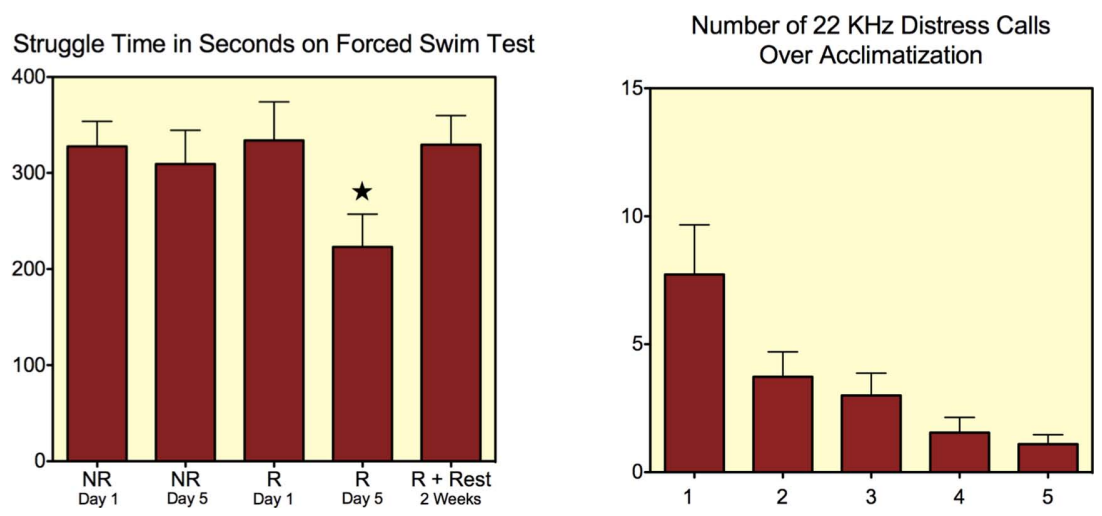

FIGURE 4 | Effects of restraint over the course of 5 days on struggling time in a forced swim test and on the emission of 22 KHz ultrasonic vocalizations. $R$, restraint; NR, no restraint; NR + Rest, no restraint and re-test after 2 weeks of rest. Star indicates significant difference between R Day 1 and R Day 5 conditions ( $p<0.05$ paired $t$-test). 
overlooked. Naert et al. (2011) report a "depressed-like state" in rats chronically exposed to repeated restraint stress. This included behavioral changes while in the elevated plus maze indicative of higher anxiety levels, changes in hedonic state as measured by the sucrose preference test, depressed locomotion and a reduction in body weight by 17\% (Naert et al., 2011). The adaptation was accompanied by HPA associated changes in brain derived neurotrophic factor (BNDF) expression, corticotropic releasing hormone $(\mathrm{CRH})$ and arginine vasopressin (AVP) levels suggesting several biological markers for plasticity within the stress axis (Naert et al., 2011).

It is important to keep in mind, however, that these studies use very intensive stress exposure schedules. Most studies looking at immobilization stress restrain animals for 90-120 $\mathrm{min}$ a day or more. King et al. (2005) reported a maximum time spent under restraint of $90 \mathrm{~min}$. Ferris et al. (2008) have had success with 60min daily sessions over the course of $4-5$ days. Animals are imaged the day after the last acclimatization session or several days later. Our laboratory has had success as well with incremental steps in restraint duration (20,40, up to $60 \mathrm{~min})$. Success is measured by the proportion of animals that are imaged without gross motion and physiological artifact. Figure 4 shows the significant reduction in $22 \mathrm{kHz}$ ultrasonic "distress" calls during 60-min sessions over 5 days. In the above-cited study, the authors employed $3 \mathrm{~h}$ daily sessions for 3 weeks (Naert et al., 2011). In addition to being stressful, an extended stress paradigm imposes a physical challenge to animals that can reduce overall activity (see results in Figure 4). Results from an unpublished study in Figure 4 show that there is reduction in time spent struggling on the fifth day of restraint in comparison to the first restraint and FST session. The reduced struggle time, or a curtailed effort to escape, may be considered a sign of learned helplessness. However, an alternative explanation is that the effort to escape on the first day of restraint and FST is reduced on day 5 because of physical fatigue. Evidence for this comes from a group in Figure $\mathbf{4}$ showing data for rats restrained for 5 days and then re-tested 2 weeks later $(\mathrm{R}+\mathrm{Rest})$. These animals recover their levels of struggle time to levels observed in the first day of testing. This result, in addition to supporting an adaptive behavioral mechanism, also suggests that experiments should ideally be carried out immediately after day 5 of restraint acclimation procedures. Animals may again increase movement if not imaged before 2 weeks (Figure 4). Reduced exposure time to intermittent daily sessions may therefore minimize the effects seen with longer chronic restraint sessions.

Evidence indicates that intensity of a stressor may have more of an impact than the duration on the subsequent stress responsiveness of the animal (Garcia et al., 2000). However, there is residual impairment of HPA ACTH responses with immobilization stress (Garcia et al., 2000). The question remains whether all stressors are equal and whether immobility stress as classically studied has the same neurobiological and behavioral impact as the head restraint used in functional neuroimaging studies. There have been a host of other studies seeking to understand adaptations to restraint stress and whether the changes involved permanent modifications of the rodents brain (causing long-term changes in the behavioral and neural responses; Kant et al., 1985; Briski and Sylvester, 1987; Pierzchala and Van Loon, 1990; Girotti et al.,
2006). This latter effect may not be entirely avoidable. Indeed, even single exposure to immobility stress can have long-term effects on behavior, such as cross-sensitization of responses to stressors (Belda et al., 2008).

\section{EXPERIMENTS IN AWAKE RATS AND DATA INTERPRETATIONS}

The methodology for imaging awake animals is recent enough that it has not yet been used across a broad spectrum of applications. The work in our laboratory has focused on studies of the effects of psychoactive substances, aggressive motivation, and the neural basis of maternal behavior during lactation. In both cases the methods employed can be of great use for studies seeking to understand neurodevelopmental changes during distinct reproductive stages of rats. The guidelines described apply to any investigation in which BOLD fMRI data are acquired. There have been significant studies employing in vitro methods assessing cerebral glucose metabolism following acute and repeated cocaine exposure (Porrino et al., 1988; Stein and Fuller, 1992, 1993; Hammer et al., 1993). Since the rewarding and psychomotor properties of cocaine are attributed to changes in neuronal and synaptic activity within mesocortical and mesolimbic systems (Einhorn et al., 1988; Chang et al., 1998), we used fMRI to investigate the neural actions of cocaine in awake animals (Febo et al., 2004b). Prior to this experiment there were several human functional imaging experiments investigating changes in brain activation following intravenous cocaine administration (Breiter et al., 1997; Kaufman et al., 1998; Li et al., 2000), however, experiments seeking to understand the developmental events leading to an addicted state cannot be studied in humans. Animal studies carried out in anesthetized rats are hampered by the use of general anesthetics for the reasons cited above (Marota et al., 2000; Mandeville et al., 2001). We used spin EPI in unconscious rats at $4.7 \mathrm{~T}$ following an intracerebroventricular injection of cocaine $(20 \mu \mathrm{g})$ in artificial cerebrospinal fluid $(10 \mu \mathrm{L})$. Within $5 \mathrm{~min}$ of injection, there was a significant increase in BOLD signal intensity in the substantia nigra, ventral tegmental area, nucleus accumbens, dorsal striatum and prefrontal cortex, as compared to vehicle controls (Figure 5). Minimal negative BOLD signal changes were observed in response to cocaine and no significant perturbations in normal cardiovascular and respiratory function. The findings demonstrated the technical feasibility of studying psychostimulant-induced brain activity using functional MRI in conscious rats. The results using BOLD fMRI corroborate findings from previous animal studies. Metabolic mapping with radiolabelled deoxyglucose showed cocaine-induced, site-specific glucose utilization in the multiple areas of the brain (London et al., 1986; Porrino et al., 1988). In a follow up study the repeated effects of cocaine were examined using the same methods. Seven days of pretreatment with cocaine significantly reduced the BOLD response to the drug. Although the lower BOLD response to cocaine appeared to be a generalized and non-specific effect, several brain areas of acutely and repeatedly treated rats did not show differences in BOLD signal intensity (namely, the dorsal prefrontal cortex, cingulate, and somatosensory cortex). In addition, the lower BOLD response was not associated with differences in cerebrovascular reactivity between the two treatment groups, as measured by brief exposure to 

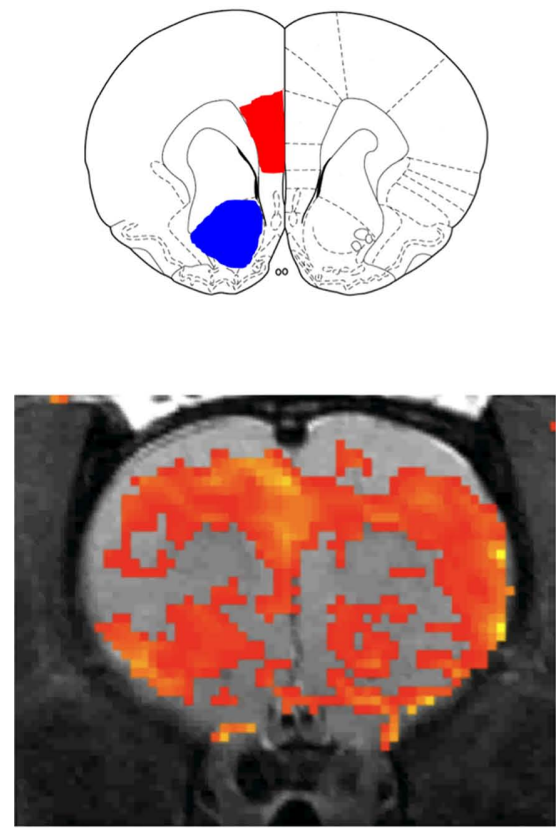

FIGURE 5 | Cocaine-stimulated increases in BOLD in the media prefrontal cortex and the nucleus accumbens. To left shows a rat coronal atlas map highlighting the medial PFC (red) and the accumbens (blue). Below is a representative rat coronal slice showing areas of increased BOLD as orange-to-yellow pixels. Plots on the right show
Medial Prefrontal Cortex

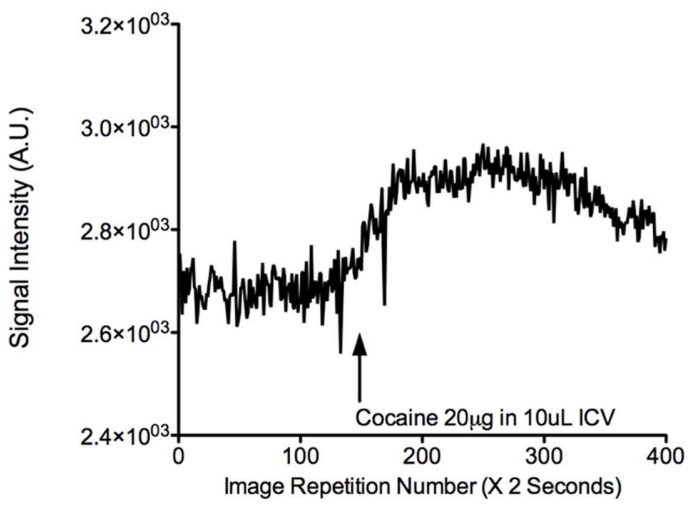

Nucleus Accumbens

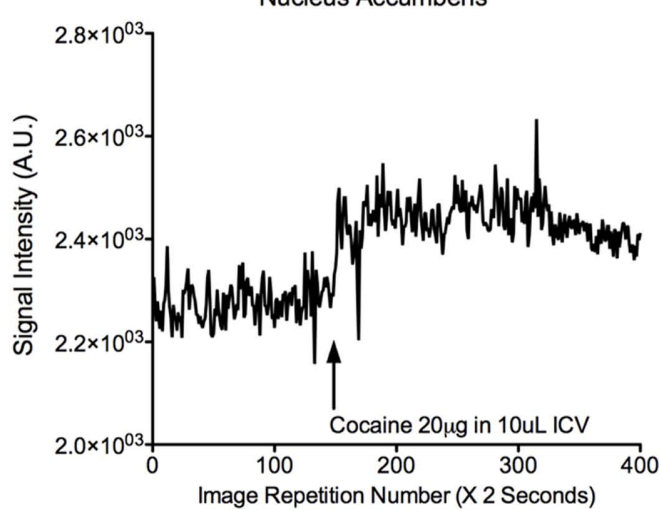

changes in BOLD over time for the representative rat. Data are expressed in arbitrary units. Arrow shows onset of cocaine injection into the lateral cerebral ventricle. Data were acquired using a $T_{2}$ weighted spin echo echo planar imaging (EPI) sequence at $4.7 \mathrm{~T}$ (effective TE $=55 \mathrm{~ms}$ and $T R=2 s$ ). hypercapnia. One explanation proposed for the decreased BOLD response observed is that it might be associated with the previously observed decreases in glucose metabolism (Hammer et al., 1993) and could also be related to reductions in basal and cocainestimulated synaptic monoamine concentrations (Imperato et al., 1992; Kalivas and Duffy, 1993; Parsons et al., 1996). Alternatively, the reduced BOLD response could be due to differences in basal cerebrovascular reactivity.

A series of experiments in awake lactating rats have been carried out using the methods described above. Many of these have focused on the neural processing of the natural suckling stimulus from pups (Febo et al., 2005b, 2008; Ferris et al., 2005; Febo and Ferris, 2007). It has been reported that suckling stimulation from pups modulates the expression of maternal behaviors in rats by promoting arched back nursing postures (Stern and Johnson, 1990; Stern et al., 2002) and slow-wave sleep (Lincoln et al., 1980; Blyton et al., 2002). The fMRI technique was used to map the cortical pattern of activity during suckling, and the stimulus was compared to artificial suction in the absence of pups and mechanical stimulation on the ventrum skin (Febo et al., 2008). During the processing of somatosensory stimuli, information coming from the landscape of peripheral sensory receptors underlying body skin surface is relayed to the cortex through the spinothalamic pathway and topographically represented in the cerebrum. In the case of the mammillae, primary afferent fibers terminate in the ipsilateral dorsal root ganglia between spinal segments C5 and L6 (Tasker et al., 1986), with afferent relays along the lateral cervical nucleus, the dorsal column nuclei and the sensory and spinal portions of the trigeminal complex (Dubois-Dauphin et al., 1985; Stern et al., 2002). In contrast with studies using c-fos assays that provide exquisite cellular spatial detail (Walsh et al., 1996; Lonstein and Stern, 1997; Lin et al., 1998; Lonstein et al., 1998; Lee et al., 1999), the detection of real-time brain activity during the actual act of nursing is limited by the very wide temporal window (usually taken 60-120 min post-stimulus). Findings from electrophysiological recordings taken from neurons in the somatosensory cortex of the anesthetized rat indicate that the receptive field for the ventrum skin surrounding the nipple area doubles in size during the lactation period (Xerri et al., 1994). It was found in the fMRI study that wide areas of the postpartum rat cerebrum exhibit 
an increase in the fMRI BOLD signal during suckling stimulation, suggesting that neural activity is modified over wide areas of the cerebral cortex in response to a rather specific stimulus (Febo et al., 2008). The artificial suckling stimulus caused a similar degree of cortical activation. Therefore, although auditory, olfactory, and non-suckling tactile stimulation from pups may contribute to cortical activity, the suckling itself is fully capable of causing a widespread cortical response. There have been experiments examining the patterns of brain activity in mothers presented with infant sensory cues, but as yet, none have investigated the effects of the lactational stimulus. Our rat studies suggest that there would be significant cortical activation not only in limbic cortical divisions, as reported previously (Lorberbaum et al., 2002), but in areas that might correspond to long-term memory storage. These are cortical representations of the suckling stimulus that might be important for the maternal-infant bond during the early lactational period. This remains to be tested in primates, including humans.

One should be cognizant of the biological underpinnings contributing to the BOLD signal in order to interpret fMRI results. A few concepts, which are based on the literature across several fields of research, have been presented in Section "Physiology of the BOLD Contrast Mechanism". The simplistic designation of "activation" or "deactivation" is often used to refer to increases in BOLD or statistically significant interactions between variables of an fMRI study. The terminology has allowed an easy interpretation of fMRI findings across many human and animal studies. However, one cannot infer neuronal excitation and inhibition without direct neurophysiological measurements. If the ultimate goal of the study is to identify and/or attribute a general role for a brain region in a task or in responding to a stimulus, then the simple terminology can be helpful. If, on the other hand, the goal is to investigate and infer complex neuronal processing then it is really not. Whatever the case, the prudent MR imager needs to keep in mind the multiple factors that play key roles in generating the BOLD signal and the statistical maps that are present in many research studies (see Figure 6). Shown in Figure 6 are several factors that underlie or influence the BOLD signal and that have been briefly discussed in the preceding sections. The cooperative synaptic activity of clusters of neurons generates neural signal changes that can be measured by LFPs. These arise to a large extent from somatodendritic fields, with large net changes in extracellular electrical sources (current leaving cells) and sinks (current entering cells). The metabolic demand generated by such activity is "more than" balanced by the delivery of energy substrates in the bloodstream (Figure 6). Concepts of neuronal and vascular mechanisms should therefore be significantly relied upon during data interpretations. This should be accompanied by a clear understanding of the nature of the stimulus (whether simple or complicated) presented to the animal during fMRI scanning. What cannot be assumed is that BOLD signal maps are maps for receptor or protein distribution, as in autoradiographic, immunohistochemical and cellular c-fos assays, or that fMRI data show functional neuroanatomical connectivity (as would be observed in studies using orthodromic stimulation of a synaptic terminal region to record spike activity from a soma in a distant site). At the backdrop of the biological underpinnings are the principles of nuclear magnetic resonance, signal processing, and statistical mapping, which are at the heart of fMRI studies. The nuclear magnetic resonance phenomenon is so disconnected from the neurophysiological underpinnings that it can make the understanding of functional neuroimaging data difficult. However, the biological link is, as stated above (See Physiology of the BOLD Contrast Mechanism), the hemodynamic mechanism that directly influences the MR signal, and that is, the ratio between $\mathrm{HbO}_{2}$ and $\mathrm{dHb}$ in the vascular and capillary bed surrounding areas of increased or decreased neuronal activity and metabolism (Figure 6). A greater value of $\mathrm{HbO}_{2} / \mathrm{dHb}$ (if one were to measure these variables directly) during stimulation vs. baseline periods is indicative of increased $\mathrm{O}_{2}$ in response to metabolic activation. As in the original Ogawa et al. (1990) work, a greater $\mathrm{O}_{2}$ tension resulted in increased local signal intensity, which is what is measured in most fMRI studies. This is most likely due to the lowered paramagnetic effects of $\mathrm{dHb}$. Statistical mapping is also a very important area in animal imaging experiments and this will not be discussed here. Suffice it to say that there are significant differences between human and animal imaging both in terms of the software used and study design that absolutely have to be taken into account. It is of the author's awareness that this is a source of great confusion to those that are not closely following the field of neuroimaging and that still find it difficult to trust the reliability of the MR methods compared with traditional techniques.

In both the cocaine experiment and the lactation study cited above one assumes that the BOLD signal changes are predominantly related to changes in neuronal activity and not only due to increased blood flow (as in the case of Figure 2 where $\mathrm{CO}_{2}$ produces increases in BOLD without expected changes in neuronal activity because of the vasodilatory effects of $\mathrm{CO}_{2}$ ). Differences in percent changes in BOLD between the different experimental conditions are expected to represent differences in neuronal activity of comparable magnitude. Therefore, if one were to carry out the same experiments using similar procedures (e.g., restraint, acclimation, stimulus delivery) but instead record synaptic activity within the regions of interest, there would be comparable differences, for example, for changes in field potential activity. There are many reasons for considering that this is the case and these were discussed above. The direct action of cocaine, for example, on preventing the reuptake of dopamine and other catecholamines stimulates synaptic activity through increased firing and neurotransmitter metabolism. Suckling stimulation and mechanical stimulation on the ventrum increases intra-cortical processing of the sensory stimulus through net changes in synaptic firing with accompanying increases in metabolism (see Figure 1). However, as stated previously one cautiously interprets fMRI data in this direction since other biological mechanisms take effect and can alter the magnitude changes in BOLD. This could include effects on cerebrovascular reactivity for instance with drug treatments or with endogenous variations in hormones (Febo et al., 2004a, 2005a). Addressing changes in CBF can be performed by using arterial spin labeling methods as in Schmidt et al. (2006) or testing cerebrovascular reactivity between groups through $\mathrm{CO}_{2}$ challenges as in Febo et al. (2004a). These procedures can provide the investigator with direct and indirect assessments of basal hemodynamics. 


\section{Physiological and Anatomical Underpinnings}

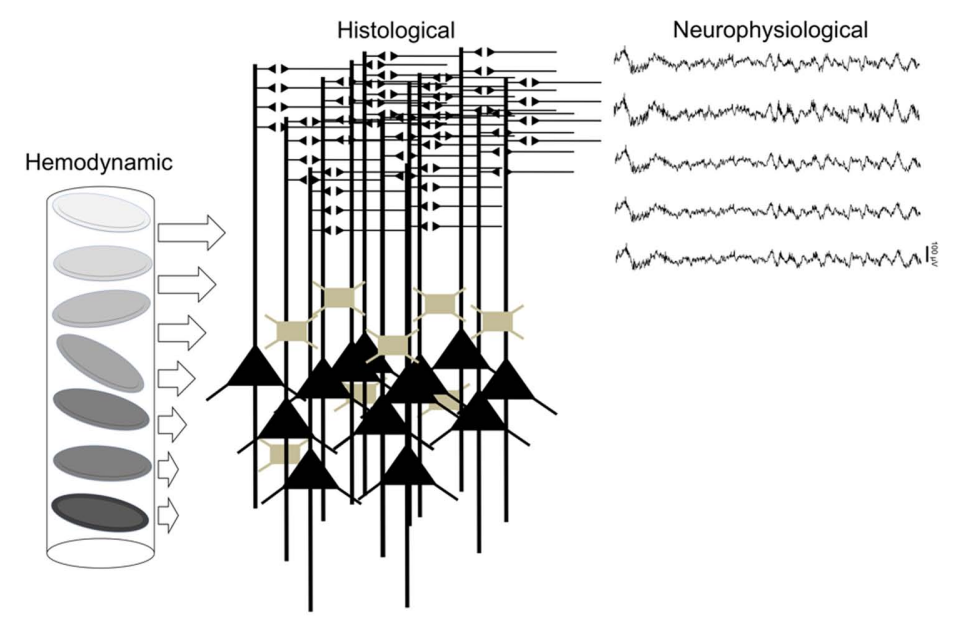

\section{Physical, Statistical and Signal Processing}

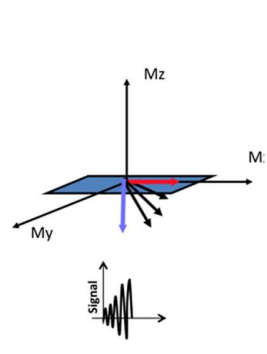

Nuclear Magnetic Resonance

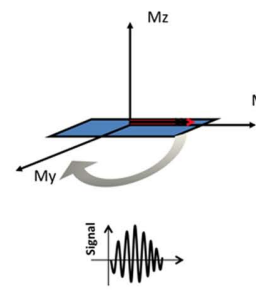

FIGURE 6 | Conceptual and technical considerations for functional magnetic resonance imaging of animals. The top images show several physiological and neuroanatomical factors that are important for data interpretations. These include knowledge of the tissue histological properties (e.g., layer specific organization of the cortex vs. heterogenous organization of other subcortical regions such as the striatum). For example, here in the middle are populations of neuronal soma typically found in layer 5 of the neocortex with overlying dendritic fields, which process incoming synaptic inputs. Electrophysiological correlates of this neural
There has been other significant research in awake animals that have primarily focused on investigating the neural actions of pharmacological agents (Chin et al., 2011), investigations of the differences in the hemodynamic response function in awake vs. anesthetized rats (Martin et al., 2006), cerebellar dependent motor learning though eye-blink conditioning in the rabbit (Miller et al., 2003), FC studies of the awake rat brain (Liang et al., 2011; Zhang et al., 2011), combined examination of sensory neural processing in specific circuits using fMRI and optogenetics in awake mice (Desai et al., 2011), and awake Rhesus macaques and marmoset monkeys (Ferris et al., 2001, 2004; Brevard et al., 2006; Goense and Logothetis, 2008). The studies support the use of awake fMRI methods in neuroscience research and have been performed using a variety of elegant and creative custom procedures that will not be discussed here. In general, all involve head restraint and many of these used some form of training of animals prior to studies. Miller et al. (2003) used the rabbit model in their studies of eye-blink conditioning. These animals are resilient to restraint stress and thus provide an interesting model for awake imaging. There were changes in cerebellar BOLD signal responses during progressive conditioning trials that closely matched patterns of electrical activity during learning (Miller et al., 2003). Desai et al. (2011) recently used optogenetic methods that pair the virally mediated expression of photorhodopsin in glutamatergic neurons of the barrel field cortex to study lightstimulated increases in neuronal activity in the somatosensory cortex of the awake mouse during fMRI. Light induced increases in neuronal activity produced BOLD signal responses in the barrel field region that were comparable to activation evoked by whisker deflection (Desai et al., 2011). This is an interesting study since it provides data on the role of excitatory activity on generation of the BOLD response but also because postsynaptic activity of pyramidal cells is considered to produce less energy expenditure compared to presynaptic activity. Therefore the BOLD responses 
here could correspond to local somatodendritic activity with the channel-rhodopsin mediated increase in activity. The combined use of fMRI and optogenetics may be an important future venue to those that are interesting in delving into the functional roles of specific neural circuits. To sum, interpretability of fMRI data is strong when used in conjunction with additional methods assessing neuroanatomy and neurophysiology and using multiple imaging modalities (BOLD and CBF). However, when the technique is used on its own it still provides important information on neural mechanisms particularly the responses to a variety of sensory stimuli. Interpretations should consider the methods employed (anesthetized vs. awake) and also the underlying assumptions of the BOLD signal as it relates to neuronal activity.

\section{ADDITIONAL CONSIDERATIONS, FUTURE DIRECTIONS, AND ALTERNATIVE APPLICATIONS}

Awake rat imaging can be used to investigate brain function and the actions of drugs in the brain, perhaps developmental processes as well. However it is important to keep in mind the underlying mechanisms of the BOLD fMRI technique when interpreting data. There are limitations to the use of the technique that mostly stem from the restriction of head movement in both anesthetized and awake preparations. This imposes an upper limit on the questions that can be asked regarding the relation of brain activity to behavior. Consider for instance the fact that motivational systems, such as the mesolimbic dopamine system, are involved in interfacing limbic and motor responses (Mogenson and Yang, 1991). Therefore, a limiting factor is that the technique lacks the ability to establish links between brain activity and many forms of motivational behavior and this is especially confounded in anesthetized rat preparations. Another factor to consider is the baseline hemodynamic state. When there are differences in the magnitude of the BOLD signal change this could originate from underlying neural mechanisms but may also be associated with changes in basal state of the cerebrovasculature. Methods are available to circumvent this latter issue using direct CBF measurements that quantitatively examine basal arterial flow and this can shed light on neuroadaptive changes contributing to differences among experimental groups.

The field of MR see's an ever-growing expansion of applications, conceptual considerations, and technical advances that will surely impact the use of animal imaging methods in the future. For example, BOLD signal decreases have not been mentioned here, although negative BOLD responses are pervasive in $\mathrm{AMRI}$ studies. There is empirical evidence for correlations between negative BOLD responses and decreased neuronal firing (Shmuel et al., 2006). The estimates from this latter study find that almost $60 \%$ of negative BOLD signal changes may correspond to reductions in multi-unit and field potential activity (Shmuel et al., 2006). However, there are also significant experiments that indicate that the negative BOLD responses are associated with "vascular-steal" (Harel et al., 2002). That is, areas adjacent to the site of activity lose blood to areas that are most active. Under normal circumstances, one of these two scenarios may explain negative BOLD responses. In other instances, high temporal resolution scans at high fields can resolve initial transient negative BOLD responses that are related to immediate increases in $\mathrm{O}_{2}$ metabolism and extraction from plasma (Kim et al., 2000). However, most fMRI studies do not report this effect since it is overridden by dramatic increases in CBF after the onset of neural activity. There are two other scenarios that relate to the negative BOLD response, these include the post-stimulus undershoot (Buxton, 2002) and conditions which result in uncoupling between $\mathrm{CBF}$ and $\mathrm{CMRO}_{2}$ (the latter exceeding CBF changes; Schridde et al., 2008). An example of this latter case is given by Schridde et al. (2008), which observed long-lasting BOLD signal reductions while at the same time measured $\mathrm{CBF}$ increases during bicuculline-induced seizures in rats. Interestingly, this was region specific since the mismatches were most prominent for the hippocampus rather than the cortex. Therefore, exceedingly high levels of $\mathrm{CMRO}_{2}$ may have occurred during seizure activity that could have resulted in negative signal responses. The negative BOLD responses that are observed in most studies that do not intend to modulate inhibitory activity are difficult to explain. More data are needed in order to understand and perhaps even modulate negative BOLD responses rather than positive BOLD responses (Desalvo et al., 2011). Finally, as discussed in Section "Physiology of the BOLD Contrast Mechanism," the Larmor equation establishes a relationship between precessional frequency and field strength. Based upon this relationship it may be possible that increasing field strength could increase signal to noise and better spatial resolution in functional images. There are several experiments that are pursuing this direction, which should be of great importance in future work employing murine models (Silva and Koretsky, 2002; Seehafer et al., 2011).

Other techniques that have not been discussed can significantly contribute to investigations in different fields of neuroscience and animal imaging. These include techniques such as manganese enhanced MRI (MEMRI), FC analysis and fiber tracking using diffusion tensor imaging (DTI). For example, in MEMRI manganese chloride is used as an intracellular contrast agent that enhances $\mathrm{T}_{1}$ signal intensity on high-resolution $\mathrm{MR}$ images. The $\mathrm{Mn}^{2+}$ ion is taken up by actively firing neurons through calcium channels and reflects synaptic activity more directly and in a quantitative manner (Aoki et al., 2002; Pautler et al., 2003). There is substantial experimental validation of the technique in its different variations. For example, one study showed a comparable match between BOLD signal and $\mathrm{T}_{1}$ enhanced signal intensity due to $\mathrm{Mn}^{2+}$ uptake in the somatosensory cortex (Duong et al., 2000). There have been many more applications of the technique (Saleem et al., 2002; Yu et al., 2005; Nairismagi et al., 2006; Chen et al., 2007). Therefore, when used correctly the technique can provide accurate information regarding the functional neuroanatomical organization of the brain. The temporal resolution is very sluggish compared to fMRI, taking several hours rather than seconds, but can still be used to examine correlations between synaptic activity and behavior ( $\mathrm{Lu}$ et al., 2007) and to investigate functional neural circuits (Saleem et al., 2002). MRI and fMRI techniques are invaluable in many neuroscience fields.

Many issues regarding anesthetized and awake animal imaging have been discussed here and continue to be investigated further. As we understand the effects of restraint, anesthetics and as more tools for preprocessing and analyzing data become available, 
applications of the technology in animal studies will prove to be an even more powerful tool for brain research. Ultimately this requires close collaborations between neuroscientists in different disciplines and engineers at academic imaging laboratories.

\section{REFERENCES}

Angenstein, F., Krautwald, K., and Scheich, H. (2011). The current functional state of local neuronal circuits controls the magnitude of a BOLD response to incoming stimuli. Neuroimage 50, 1364-1375.

Aoki, I., Tanaka, C., Takegami, T., Ebisu, T., Umeda, M., Fukunaga, M., Fukuda, K., Silva, A. C., Koretsky, A. P., and Naruse, S. (2002). Dynamic activity-induced manganesedependent contrast magnetic resonance imaging (DAIM MRI). Magn. Reson. Med. 48, 927-933.

Attwell, D., and Iadecola, C. (2002). The neural basis of functional brain imaging signals. Trends Neurosci. 25, 621-625.

Austin, V. C., Blamire, A. M., Allers, K. A., Sharp, T., Styles, P., Matthews, P. M., and Sibson, N. R. (2005). Confounding effects of anesthesia on functional activation in rodent brain: a study of halothane and alpha-chloralose anesthesia. $\mathrm{Neu}$ roimage $24,92-100$.

Bandettini, P. A., and Wong, E. C. (1997). A hypercapnia-based normalization method for improved spatial localization of human brain activation with fMRI. NMR Biomed. 10, 197-203.

Bandettini, P. A., Wong, E. C., Hinks, R. S., Tikofsky, R. S., and Hyde, J. S. (1992). Time course EPI of human brain function during task activation. Magn. Reson. Med. 25, 390-397.

Barnum, C. J., Blandino, P. Jr., and Deak, T. (2007). Adaptation in the corticosterone and hyperthermic responses to stress following repeated stressor exposure. $\mathrm{J}$. $\mathrm{Neu}$ roendocrinol. 19, 632-642.

Bartels, A., and Zeki, S. (2004). The neural correlates of maternal and romantic love. Neuroimage 21, 1155-1166.

Belda, X., Fuentes, S., Nadal, R., and Armario, A. (2008). A single exposure to immobilization causes longlasting pituitary-adrenal and behavioral sensitization to mild stressors. Horm. Behav. 54, 654-661.

Bhattacharyya, P. K., and Lowe, M. J. (2004). Cardiac-induced physiologic noise in tissue is a direct observation of cardiac-induced fluctuations. Magn. Reson. Imaging 22, 9-13.
Blyton, D. M., Sullivan, C. E., and Edwards, N. (2002). Lactation is associated with an increase in slowwave sleep in women. J. Sleep Res. 11, 297-303.

Breiter, H. C., Gollub, R. L., Weisskoff, R. M., Kennedy, D. N., Makris, N., Berke, J. D., Goodman, J. M., Kantor, H. L., Gastfriend, D. R., Riorden, J. P., Mathew, R. T., Rosen, B. R., and Hyman, S. E. (1997). Acute effects of cocaine on human brain activity and emotion. Neuron 19, 591-611.

Brevard, M. E., Duong, T. Q., King, J. A., and Ferris, C. F. (2003). Changes in MRI signal intensity during hypercapnic challenge under conscious and anesthetized conditions. Magn. Reson. Imaging 21, 995-1001.

Brevard, M. E., Meyer, J. S., Harder, J. A., and Ferris, C. F. (2006). Imaging brain activity in conscious monkeys following oral MDMA ("ecstasy”). Magn. Reson. Imaging 24, 707-714.

Briski, K. P., and Sylvester, P. W. (1987). Effects of repetitive daily acute stress on pituitary $\mathrm{LH}$ and prolactin release during exposure to the same stressor or a second novel stress. Psychoneuroendocrinology 12, 429-437.

Buxton, R. B. (2002). Introduction to Functional Magnetic Resonance Imaging: Principles and Techniques. New York: Cambridge University Press.

Buzsaki, G., Kaila, K., and Raichle, M. (2007). Inhibition and brain work. Neuron 56, 771-783.

Chang, J.Y., Janak, P. H., and Woodward, D. J. (1998). Comparison of mesocorticolimbic neuronal responses during cocaine and heroin selfadministration in freely moving rats. J. Neurosci. 18, 3098-3115.

Chen, W., Shields, J., Huang, W., and King, J. A. (2009). Female fear: influence of estrus cycle on behavioral response and neuronal activation. Behav. Brain Res. 201, 8-13.

Chen, W., Tenney, J., Kulkarni, P., and King, J. A. (2007). Imaging unconditioned fear response with manganese-enhanced MRI (MEMRI). Neuroimage 37, 221-229.

Chin, C. L., Fox, G. B., Hradil, V. P., Osinski, M. A., Mcgaraughty, S. P., Skoubis, P. D., Cox, B. F., and Luo, Y. (2006). Pharmacological MRI in awake rats reveals neural activity in area postrema and nucleus tractus solitarius: relevance as a

\section{ACKNOWLEDGMENTS}

The author would like to thank Dr. Josephine Todrank and Martha Caffrey for the helpful comments and suggestions. Support is provided by NIH grant DA019946.

potential biomarker for detecting drug-induced emesis. Neuroimage 33, 1152-1160.

Chin, C. L., Upadhyay, J., Marek, G. J., Baker, S. J., Zhang, M., Mezler, M., Fox, G. B., and Day, M. (2011). Awake rat pharmacological magnetic resonance imaging as a translational pharmacodynamic biomarker: metabotropic glutamate $2 / 3$ agonist modulation of ketamine-induced blood oxygenation level dependence signals. J. Pharmacol. Exp. Ther. 336, 709-715.

Cohen, E. R., Ugurbil, K., and Kim, S. G. (2002). Effect of basal conditions on the magnitude and dynamics of the blood oxygenation level-dependent fMRI response. J. Cereb. Blood Flow Metab. 22, 1042-1053.

Davis, T. L., Kwong, K. K., Weisskoff, R. M., and Rosen, B. R. (1998). Calibrated functional MRI: mapping the dynamics of oxidative metabolism. Proc. Natl. Acad. Sci. U.S.A. 95, 1834-1839.

Desai, M., Kahn, I., Knoblich, U., Bernstein, J., Atallah, H., Yang, A., Kopell, N., Buckner, R. L., Graybiel, A. M., Moore, C. I., and Boyden, E. S. (2011). Mapping brain networks in awake mice using combined optical neural control and fMRI. J. Neurophysiol. 105, 1393-1405.

Desalvo, M. N., Schridde, U., Mishra, A. M., Motelow, J. E., Purcaro, M. J., Danielson, N., Bai, X., Hyder, F., and Blumenfeld, H. (2011). Focal BOLD fMRI changes in bicucullineinduced tonic-clonic seizures in the rat. Neuroimage 50, 902-909.

Dhabhar, F. S., Mcewen, B. S., and Spencer, R. L. (1997). Adaptation to prolonged or repeated stress comparison between rat strains showing intrinsic differences in reactivity to acute stress. Neuroendocrinology 65, 360-368.

Doty, F. D., Entzminger, G., Kulkarni, J., Pamarthy, K., and Staab, J. P. (2007). Radio frequency coil technology for small-animal MRI. NMR. Biomed. 20, 304-325.

Douglas, R., Markram, H., and Martin, K. (2004). "Neocortex," in The Synaptic Organization of the Brain, ed. G. M. Sheperd, 5th Edn (New York: Oxford University Press), 499-558.

Dubois-Dauphin, M., Armstrong, W. E., Tribollet, E., and Dreifuss, J.
J. (1985). Somatosensory systems and the milk-ejection reflex in the rat. II. The effects of lesions in the ventroposterior thalamic complex, dorsal columns and lateral cervical nucleus-dorsolateral funiculus. Neuroscience 15, 1131-1140.

Duong, T. Q., Silva, A. C., Lee, S. P., and Kim, S. G. (2000). Functional MRI of calcium-dependent synaptic activity: cross correlation with CBF and BOLD measurements. Magn. Reson. Med. 43, 383-392.

Duong, T. Q., Yacoub, E., Adriany, G., Hu, X., Ugurbil, K., and Kim, S. G. (2003). Microvascular BOLD contribution at 4 and $7 \mathrm{~T}$ in the human brain: gradient-echo and spin-echo fMRI with suppression of blood effects. Magn. Reson. Med. 49, 1019-1027.

Eger, E. I. II, and Johnson, B. H. (1987). Rates of awakening from anesthesia with I-653, halothane, isoflurane, and sevoflurane: a test of the effect of anesthetic concentration and duration in rats. Anesth. Analg. 66, 977-982.

Einhorn, L. C., Johansen, P. A., and White, F. J. (1988). Electrophysiological effects of cocaine in the mesoaccumbens dopamine system: studies in the ventral tegmental area. $J$. Neurosci. 8, 100-112.

Febo, M., and Ferris, C. F. (2007). Development of cocaine sensitization before pregnancy affects subsequent maternal retrieval of pups and prefrontal cortical activity during nursing. Neuroscience 148, 400-412.

Febo, M., Ferris, C. F., and Segarra, A. C. (2005a). Estrogen influences cocaine-induced blood oxygen level-dependent signal changes in female rats. J. Neurosci. 25, 1132-1136.

Febo, M., Numan, M., and Ferris, C. F. (2005b). Functional magnetic resonance imaging shows oxytocin activates brain regions associated with mother-pup bonding during suckling. J. Neurosci. 25, 11637-11644.

Febo, M., and Pira, A. S. (2011). Increased BOLD activation to predator stressor in subiculum and midbrain of amphetamine-sensitized maternal rats. Brain Res. 1382, $118-127$. 
Febo, M., Segarra, A. C., Nair, G., Schmidt, K., Duong, T. Q., and Ferris, C. F. (2004a). The neural consequences of repeated cocaine exposure revealed by functional MRI in awake rats. Neuropsychopharmacology 30, 936-943.

Febo, M., Segarra, A. C., Tenney, J. R., Brevard, M. E., Duong, T. Q., and Ferris, C. F. (2004b). Imaging cocaine-induced changes in the mesocorticolimbic dopaminergic system of conscious rats. J. Neurosci. Methods 139, 167-176.

Febo, M., Stolberg, T. L., Numan, M., Bridges, R. S., Kulkarni, P., and Ferris, C. F. (2008). Nursing stimulation is more than tactile sensation: it is a multisensory experience. Horm. Behav. 54, 330-339.

Ferris, C. F., Febo, M., Luo, F., Schmidt, K., Brevard, M., Harder, J. A., Kulkarni, P., Messenger, T., and King, J. A. (2006). Functional magnetic resonance imaging in conscious animals: a new tool in behavioural neuroscience research. J. Neuroendocrinol. 18, 307-318.

Ferris, C. F., Kulkarni, P., Sullivan, J. M. Jr., Harder, J. A., Messenger, T. L., and Febo, M. (2005). Pup suckling is more rewarding than cocaine: evidence from functional magnetic resonance imaging and three-dimensional computational analysis. J. Neurosci. 25, 149-156.

Ferris, C. F., Snowdon, C. T., King, J. A., Duong, T. Q., Ziegler, T. E., Ugurbil, K., Ludwig, R., Schultz-Darken, N. J., Wu, Z., Olson, D. P., Sullivan Jr, J. M., Tannenbaum, P. L., and Vaughan, J. T. (2001). Functional imaging of brain activity in conscious monkeys responding to sexually arousing cues. Neuroreport 12, 2231-2236.

Ferris, C. F., Snowdon, C. T., King, J. A., Sullivan, J. M. Jr., Ziegler, T. E., Olson, D. P., Schultz-Darken, N. J., Tannenbaum, P. L., Ludwig, R., Wu, Z., Einspanier, A., Vaughan, J. T., and Duong, T. Q. (2004). Activation of neural pathways associated with sexual arousal in non-human primates. J. Magn. Reson. Imaging 19, 168-175.

Ferris, C. F., Stolberg, T., Kulkarni, P., Murugavel, M., Blanchard, R., Blanchard, D. C., Febo, M., Brevard, M., and Simon, N. G. (2008). Imaging the neural circuitry and chemical control of aggressive motivation. BMC Neurosci. 9, 111. doi: 10.1186/1471-2202-9-111

Fox, P. T., and Raichle, M. E. (1986). Focal physiological uncoupling of cerebral blood flow and oxidative metabolism during somatosensory stimulation in human subjects. Proc. Natl. Acad. Sci. U.S.A. 83, 1140-1144.

Fox, P. T., Raichle, M. E., Mintun, M. A., and Dence, C. (1988). Nonoxidative glucose consumption during focal physiologic neural activity. Science 241, 462-464.

Freire, L., and Mangin, J. F. (2001). Motion correction algorithms may create spurious brain activations in the absence of subject motion. $\mathrm{Neu}$ roimage 14, 709-722.

Garcia, A., Marti, O., Valles, A., DalZotto, S., and Armario, A. (2000). Recovery of the hypothalamicpituitary-adrenal response to stress. Effect of stress intensity, stress duration and previous stress exposure. Neuroendocrinology 72, 114-125.

Genovese, C. R., Lazar, N. A., and Nichols, T. (2002). Thresholding of statistical maps in functional neuroimaging using the false discovery rate. Neuroimage 15, 870-878.

Girotti, M., Pace, T. W., Gaylord, R. I., Rubin, B. A., Herman, J. P., and Spencer, R. L. (2006). Habituation to repeated restraint stress is associated with lack of stress-induced c-fos expression in primary sensory processing areas of the rat brain. Neuroscience 138, 1067-1081.

Goense, J. B., and Logothetis, N. K. (2006). Laminar specificity in monkey V1 using high-resolution SEfMRI. Magn. Reson. Imaging 24, 381-392.

Goense, J. B., and Logothetis, N. K. (2008). Neurophysiology of the BOLD fMRI signal in awake monkeys. Curr. Biol. 18, 631-640.

Gollub, R. L., Breiter, H. C., Kantor, H., Kennedy, D., Gastfriend, D., Mathew, R. T., Makris, N., Guimaraes, A., Riorden, J., Campbell, T., Foley, M., Hyman, S. E., Rosen, B., and Weisskoff, R. (1998). Cocaine decreases cortical cerebral blood flow but does not obscure regional activation in functional magnetic resonance imaging in human subjects. J. Cereb. Blood Flow Metab. 18 724-734.

Greenberg, D. S., Houweling, A. R., and Kerr, J. N. (2008). Population imaging of ongoing neuronal activity in the visual cortex of awake rats. Nat. Neurosci. 11, 749-751.

Haleem, D. J. (1996). Adaptation to repeated restraint stress in rats: failure of ethanol-treated rats to adapt in the stress schedule. Alcohol Alcohol. 31, 471-477.

Hammer, R. P. Jr., Pires, W. S., Markou, A., and Koob, G. F. (1993).
Withdrawal following cocaine selfadministration decreases regional cerebral metabolic rate in critical brain reward regions. Synapse 14, 73-80.

Harel, N., Lee, S. P., Nagaoka, T., Kim, D. S., and Kim, S. G. (2002). Origin of negative blood oxygenation leveldependent fMRI signals. J. Cereb. Blood Flow Metab. 22, 908-917.

Hartikainen, K. M., Rorarius, M., Perakyla, J. J., Laippala, P. J., and Jantti, V. (1995). Cortical reactivity during isoflurane burst-suppression anesthesia. Anesth. Analg. 81, 1223-1228.

Huttunen, J. K., Grohn, O., and Penttonen, M. (2008). Coupling between simultaneously recorded BOLD response and neuronal activity in the rat somatosensory cortex. Neuroimage 39, 775-785.

Hyder, F., Rothman, D. L., and Shulman, R. G. (2002). Total neuroenergetics support localized brain activity: implications for the interpretation of fMRI. Proc. Natl. Acad. Sci. U.S.A. 99, 10771-10776.

Imas, O. A., Ropella, K. M., Ward, B. D., Wood, J. D., and Hudetz, A. G. (2005). Volatile anesthetics enhance flash-induced gamma oscillations in rat visual cortex. Anesthesiology 102, 937-947.

Imas, O. A., Ropella, K. M., Wood, J. D., and Hudetz, A. G. (2004). Halothane augments event-related gamma oscillations in rat visual cortex. Neuroscience 123, 269-278.

Imperato, A., Mele, A., Scrocco, M. G., and Puglisi-Allegra, S. (1992). Chronic cocaine alters limbic extracellular dopamine. Neurochemical basis for addiction. Eur. J. Pharmacol. 212, 299-300.

Kalivas, P. W., and Duffy, P. (1993). Time course of extracellular dopamine and behavioral sensitization to cocaine. I. Dopamine axon terminals. J. Neurosci. 13, 266-275.

Kant, G. J., Eggleston, T., LandmanRoberts, L., Kenion, C. C., Driver, G. C., and Meyerhoff, J. L. (1985). Habituation to repeated stress is stressor specific. Pharmacol. Biochem. Behav. 22, 631-634.

Kasischke, K. A., Vishwasrao, H. D. Fisher, P. J., Zipfel, W. R., and Webb, W. W. (2004). Neural activity triggers neuronal oxidative metabolism followed by astrocytic glycolysis. Science 305, 99-103.

Kaufman, M. J., Levin, J. M., Maas, L. C., Rose, S. L., Lukas, S. E., Mendelson, J. H., Cohen, B. M., and Renshaw, P. F. (1998). Cocaine decreases relative cerebral blood volume in humans: a dynamic susceptibility contrast magnetic resonance imaging study. Psychopharmacology (Berl.) 138, 7681.

Kennerley, A. J., Berwick, J., Martindale, J., Johnston, D., Papadakis, N., and Mayhew, J. E. (2005). Concurrent fMRI and optical measures for the investigation of the hemodynamic response function. Magn. Reson. Med. 54, 354-365.

Kim, D. S., Duong, T. Q., and Kim, S. G. (2000). High-resolution mapping of iso-orientation columns by fMRI. Nat. Neurosci. 3, 164-169.

King, J. A., Garelick, T. S., Brevard, M. E., Chen, W., Messenger, T. L., Duong, T. Q., and Ferris, C. F. (2005). Procedure for minimizing stress for fMRI studies in conscious rats. J. Neurosci. Methods 148, 154-160.

Krishnan, V., and Nestler, E. J. (2008). The molecular neurobiology of depression. Nature 455, 894-902.

Lahti, K. M., Ferris, C. F., Li, F., Sotak, C. H., and King, J. A. (1998). Imaging brain activity in conscious animals using functional MRI. J. Neurosci. Methods 82, 75-83.

Lahti, K. M., Ferris, C. F., Li, F., Sotak, C. H., and King, J. A. (1999). Comparison of evoked cortical activity in conscious and propofol-anesthetized rats using functional MRI. Magn. Reson. Med. 41, 412-416.

Lee, A., Li, M., Watchus, J., and Fleming, A. S. (1999). Neuroanatomical basis of maternal memory in postpartum rats: selective role for the nucleus accumbens. Behav. Neurosci. 113, 523-538.

Lee, S. P., Duong, T. Q., Yang, G., Iadecola, C., and Kim, S. G. (2001) Relative changes of cerebral arterial and venous blood volumes during increased cerebral blood flow: implications for BOLD fMRI. Magn Reson. Med. 45, 791-800.

Li, S. J., Biswal, B., Li, Z., Risinger, R., Rainey, C., Cho, J. K., Salmeron, B. J., and Stein, E. A. (2000). Cocaine administration decreases functional connectivity in human primary visual and motor cortex as detected by functional MRI. Magn. Reson. Med. 43, 45-51.

Liang, Z., King, J., and Zhang, N. Uncovering intrinsic connectional architecture of functional networks in awake rat brain. (2011). J. Neurosci. 31, 3776-3783.

Lin, S. H., Miyata, S., Matsunaga, W., Kawarabayashi, T., Nakashima, T., and Kiyohara, T. (1998). Metabolic mapping of the brain in pregnant, parturient and lactating rats using fos immunohistochemistry. Brain Res. 787, 226-236. 
Lincoln, D. W., Hentzen, K., Hin, T., Van Der Schoot, P., Clarke, G., and Summerlee, A. J. (1980). Sleep: a prerequisite for reflex milk ejection in the rat. Exp. Brain Res. 38, 151-162.

Liu, X., Zhu, X. H., Zhang, Y., and Chen, W. (2011). Neural origin of spontaneous hemodynamic fluctuations in rats under burst-suppression anesthesia condition. Cereb. Cortex 21, 374-384.

Logothetis, N. K. (2008). What we can do and what we cannot do with fMRI. Nature 453, 869-878.

Logothetis, N. K., Pauls, J., Augath, M., Trinath, T., and Oeltermann, A. (2001). Neurophysiological investigation of the basis of the fMRI signal. Nature 412, 150-157.

London, E. D., Wilkerson, G., Goldberg, S. R., and Risner, M. E. (1986). Effects of L-cocaine on local cerebral glucose utilization in the rat. Neurosci. Lett. 68, 73-78.

Lonstein, J. S., Simmons, D. A., Swann, J. M., and Stern, J. M. (1998). Forebrain expression of $\mathrm{c}$-fos due to active maternal behaviour in lactating rats. Neuroscience 82, 267-281.

Lonstein, J. S., and Stern, J. M. (1997). Somatosensory contributions to cfos activation within the caudal periaqueductal gray of lactating rats: effects of perioral, rooting, and suckling stimuli from pups. Horm. Behav. $32,155-166$.

Lorberbaum, J. P., Newman, J. D., Horwitz, A. R., Dubno, J. R., Lydiard, R. B., Hamner, M. B., Bohning, D. E., and George, M. S. (2002). A potential role for thalamocingulate circuitry in human maternal behavior. Biol. Psychiatry 51, 431-445.

Lu, H., Xi, Z. X., Gitajn, L., Rea, W., Yang, Y., and Stein, E. A. (2007). Cocaine-induced brain activation detected by dynamic manganeseenhanced magnetic resonance imaging (MEMRI). Proc. Natl. Acad. Sci. U.S.A. 104, 2489-2494.

Ludwig, R., Bodgdanov, G., King, J., Allard, A., and Ferris, C. F. (2004). A dual RF resonator system for highfield functional magnetic resonance imaging of small animals. J. Neurosci. Methods 132, 125-135.

Malonek, D., Dirnagl, U., Lindauer, U., Yamada, K., Kanno, I., and Grinvald, A. (1997). Vascular imprints of neuronal activity: relationships between the dynamics of cortical blood flow, oxygenation, and volume changes following sensory stimulation. Proc. Natl. Acad. Sci. U.S.A. 94, 14826-14831.

Malonek, D., and Grinvald, A. (1996). Interactions between electrical activity and cortical microcirculation revealed by imaging spectroscopy: implications for functional brain mapping. Science 272, 551-554.

Mandeville, J. B., Jenkins, B. G., Kosofsky, B. E., Moskowitz, M. A., Rosen, B. R., and Marota, J. J. (2001). Regional sensitivity and coupling of BOLD and CBV changes during stimulation of rat brain. Magn. Reson. Med. 45, 443-447.

Marota, J. J., Mandeville, J. B., Weisskoff, R. M., Moskowitz, M. A., Rosen, B. R., and Kosofsky, B. E. (2000). Cocaine activation discriminates dopaminergic projections by temporal response: an fMRI study in Rat. Neuroimage 11, 13-23.

Martin, C., Martindale, J., Berwick, J. and Mayhew, J. (2006). Investigating neural-hemodynamic coupling and the hemodynamic response function in the awake rat. Neuroimage 32, $33-48$.

Masamoto, K., Fukuda, M., Vazquez, A., and Kim, S. G. (2009). Dosedependent effect of isoflurane on neurovascular coupling in rat cerebral cortex. Eur. J. Neurosci. 30, 242-250.

Melia, K. R., Ryabinin, A. E., Schroeder, R., Bloom, F. E., and Wilson, M. C. (1994). Induction and habituation of immediate early gene expression in rat brain by acute and repeated restraint stress. J. Neurosci. 14, 5929-5938.

Miller, M. J., Chen, N. K., Li, L., Tom, B., Weiss, C., Disterhoft, J. F., and Wyrwicz, A. M. (2003). fMRI of the conscious rabbit during unilateral classical eyeblink conditioning reveals bilateral cerebellar activation. J. Neurosci. 23, 11753-11758.

Mogenson, G. J., and Yang, C. R. (1991). The contribution of basal forebrain to limbic-motor integration and the mediation of motivation to action. Adv. Exp. Med. Biol. 295, 267-290.

Nadasdy, Z., Csicsvari, J., Penttonen, M., Hetke, J., Wise, K., and Buzsaki, G. (1998). "Extracellular recording and analysis of neuronal activity: from single cells to ensembles," in Neuronal Ensembles: Strategies for Recording and Decoding, 1st Edn, eds H. Eichenbaum and J. L. Davis (New York: Wiley-Liss), 17-56.

Naert, G., Ixart, G., Maurice, T., Tapia-Arancibia, L., and Givalois, L. (2011). Brain-derived neurotrophic factor and hypothalamic-pituitaryadrenal axis adaptation processes in a depressive-like state induced by chronic restraint stress. Mol. Cell. Neurosci. 46, 55-66.

Nairismagi, J., Pitkanen, A., Narkilahti, S., Huttunen, J., Kauppinen, R. A., and Grohn, O. H. (2006).
Manganese-enhanced magnetic resonance imaging of mossy fiber plasticity in vivo. Neuroimage 30 130-135.

Nakao, Y., Itoh, Y., Kuang, T. Y., Cook, M., Jehle, J., and Sokoloff, L. (2001). Effects of anesthesia on functional activation of cerebral blood flow and metabolism. Proc. Natl. Acad. Sci. U.S.A. 98, 7593-7598.

Nitschke, J. B., Nelson, E. E., Rusch, B. D., Fox, A. S., Oakes, T. R., and Davidson, R. J. (2004). Orbitofrontal cortex tracks positive mood in mothers viewing pictures of their newborn infants. Neuroimage 21, 583-592.

Ogawa, S., Lee, T. M., Kay, A. R., and Tank, D. W. (1990). Brain magnetic resonance imaging with contrast dependent on blood oxygenation. Proc. Natl. Acad. Sci. U.S.A. 87 9868-9872.

Ogawa, S., Tank, D. W., Menon, R., Ellermann, J. M., Kim, S. G., Merkle, H. and Ugurbil, K. (1992). Intrinsic signal changes accompanying sensory stimulation: functional brain mapping with magnetic resonance imaging. Proc. Natl. Acad. Sci. U.S.A. 89 , 5951-5955.

Parry, T. J., and Mcelligott, J. G. (1993). A method for restraining awake rats using head immobilization. Physiol. Behav. 53, 1011-1015.

Parsons, L. H., Koob, G. F., and Weiss, F. (1996). Extracellular serotonin is decreased in the nucleus accumbens during withdrawal from cocaine self-administration. Behav. Brain Res. 73, 225-228.

Pauling, L., and Coryell, C. D. (1936). The magnetic properties and structure of hemoglobin, oxyhemoglobin and carbonmonoxyhemoglobin. Proc. Natl. Acad. Sci. U.S.A. 22, 210-216.

Pautler, R. G., Mongeau, R., and Jacobs, R. E. (2003). In vivo transsynaptic tract tracing from the murine striatum and amygdala utilizing manganese enhanced MRI (MEMRI). Magn. Reson. Med. 50, 33-39.

Paxinos, G., and Watson, C. (1997). The Rat Brain in Stereotaxic Coordinates. Boston: Academic Press

Peeters, R. R., Tindemans, I., De Schutter, E., and Van Der Linden, A. (2001). Comparing BOLD fMRI signal changes in the awake and anesthetized rat during electrical forepaw stimulation. Magn. Reson. Imaging $19,821-826$.

Peeters, R. R., and Van Der Linden, A. (2002). A data post-processing protocol for dynamic MRI data to discriminate brain activity from global physiological effects. Magn. Reson Imaging 20, 503-510.

Pierzchala, K., and Van Loon, G. R. (1990). Plasma native and peptidase-derivable Met-enkephalin responses to restraint stress in rats. Adaptation to repeated restraint. J. Clin. Invest. 85, 861-873.

Porrino, L. J., Domer, F. R., Crane, A. M., and Sokoloff, L. (1988). Selective alterations in cerebral metabolism within the mesocorticolimbic dopaminergic system produced by acute cocaine administration in rats. Neuropsychopharmacology 1 , 109-118.

Poser, B. A., and Norris, D. G. (2007). Fast spin echo sequences for BOLD functional MRI. MAGMA 20, 11-17.

Purdon, P. L., and Weisskoff, R. M. (1998). Effect of temporal autocorrelation due to physiological noise and stimulus paradigm on voxellevel false-positive rates in fMRI Hum. Brain Mapp. 6, 239-249.

Sachdev, R. N., Champney, G. C., Lee, H., Price, R. R., Pickens, D. R. III, Morgan, V. L., Stefansic, J. D., Melzer, P., and Ebner, F. F. (2003). Experimental model for functional magnetic resonance imaging of somatic sensory cortex in the unanesthetized rat. Neuroimage 19, 742-750.

Saleem, K. S., Pauls, J. M., Augath, M., Trinath, T., Prause, B. A., Hashikawa, T., and Logothetis, N. K. (2002) Magnetic resonance imaging of neuronal connections in the macaque monkey. Neuron 34, 685-700.

Schmidt, K. F., Febo, M., Shen, Q., Luo, F., Sicard, K. M., Ferris, C. F., Stein, E A., and Duong, T. Q. (2006). Hemodynamic and metabolic changes induced by cocaine in anesthetized rat observed with multimodal functional MRI. Psychopharmacology (Berl.) 185, 479-486.

Schridde, U., Khubchandani, M., Motelow, J. E., Sanganahalli, B. G., Hyder, F., and Blumenfeld, $\mathrm{H}$ (2008). Negative BOLD with large increases in neuronal activity. Cereb. Cortex 18, 1814-1827.

Seehafer, J. U., Kalthoff, D., Farr, T. D., Wiedermann, D., and Hoehn, M (2011). No increase of the blood oxygenation level-dependent functional magnetic resonance imaging signal with higher field strength: implications for brain activation studies. Neurosci. 30, 5234-5241.

Sheth, S. A., Nemoto, M., Guiou, M., Walker, M., Pouratian, N., and Toga, A. W. (2004). Linear and nonlinear relationships between neuronal activity, oxygen metabolism, and hemodynamic responses. Neuron 42 , 347-355. 
Shmuel, A., Augath, M., Oeltermann, A., and Logothetis, N. K. (2006). Negative functional MRI response correlates with decreases in neuronal activity in monkey visual area $\mathrm{V} 1$. Nat. Neurosci. 9, 569-577.

Shmuel, A., Yacoub, E., Pfeuffer, J., Van De Moortele, P. F., Adriany, G., Hu, X., and Ugurbil, K. (2002). Sustained negative BOLD, blood flow and oxygen consumption response and its coupling to the positive response in the human brain. Neuron 36, 1195-1210.

Sicard, K., Shen, Q., Brevard, M. E., Sullivan, R., Ferris, C. F., King, J. A., and Duong, T. Q. (2003). Regional cerebral blood flow and BOLD responses in conscious and anesthetized rats under basal and hypercapnic conditions: implications for functional MRI studies. J. Cereb. Blood Flow Metab. 23, 472-481.

Silva, A. C., and Koretsky, A. P. (2002). Laminar specificity of functional MRI onset times during somatosensory stimulation in rat. Proc. Natl. Acad. Sci. U.S.A. 99, 15182-15187.

Stamp, J., and Herbert, J. (2001). Corticosterone modulates autonomic responses and adaptation of central immediate-early gene expression to repeated restraint stress. $\mathrm{Neu}$ roscience $107,465-479$.

Stein, E. A., and Fuller, S. A. (1992). Selective effects of cocaine on regional cerebral blood flow in the rat. J. Pharmacol. Exp. Ther. 262, 327-334.

Stein, E. A., and Fuller, S. A. (1993). Cocaine's time action profile on regional cerebral blood flow in the rat. Brain Res. 626, 117-126.

Stern, J. M., and Johnson, S. K. (1990). Ventral somatosensory determinants of nursing behavior in Norway rats. I. Effects of variations in the quality and quantity of pup stimuli. Physiol. Behav. 47, 993-1011.

Stern, J. M., Yu, Y. L., and Crockett, D. P. (2002). Dorsolateral columns of the spinal cord are necessary for both suckling-induced neuroendocrine reflexes and the kyphotic nursing posture in lactating rats. Brain Res. 947, 110-121.

Strathearn, L., Li, J., Fonagy, P., and Montague, P. R. (2008). What's in a smile? Maternal brain responses to infant facial cues. Pediatrics 122, 40-51.

Tasker, J. G., Theodosis, D. T., and Poulain, D. A. (1986). Afferent projections from the mammary glands to the spinal cord in the lactating rat - I. A neuroanatomical study using the transganglionic transport of horseradish peroxidasewheatgerm agglutinin. Neuroscience 19, 495-509.

Thompson, J. K., Peterson, M. R., and Freeman, R. D. (2003). Singleneuron activity and tissue oxygenation in the cerebral cortex. Science 299, 1070-1072.

Tian, P., Teng, I. C., May, L. D., Kurz, R., Lu, K., Scadeng, M., Hillman, E. M., De Crespigny, A. J., D'arceuil, H. E., Mandeville, J. B., Marota, J. J., Rosen, B. R., Liu, T. T., Boas, D. A., Buxton, R. B., Dale, A. M., and Devor, A. (2011). Cortical depth-specific microvascular dilation underlies laminar differences in blood oxygenation leveldependent functional MRI signal. Proc. Natl. Acad. Sci. U.S.A. 107, 15246-15251.

Tornatzky, W., and Miczek, K. A. (1993). Long-term impairment of autonomic circadian rhythms after brief intermittent social stress. Physiol. Behav. 53, 983-993.

Ugurbil, K., Adriany, G., Andersen, P., Chen, W., Garwood, M., Gruetter, R., Henry, P. G., Kim, S. G., Lieu, H., Tkac, I., Vaughan, T., Van De Moortele, P. F., Yacoub, E., and Zhu, X. H. (2003). Ultrahigh field magnetic resonance imaging and spectroscopy. Magn. Reson. Imaging 21, 1263-1281.

Walsh, C. J., Fleming, A. S., Lee, A. and Magnusson, J. E. (1996). The effects of olfactory and somatosensory desensitization on Fos-like immunoreactivity in the brains of pup-exposed postpartum rats. Behav. Neurosci. 110, 134-153.

Wang, K., Van Meer, M. P., Van Der Marel, K., Van Der Toorn, A., Xu, L., Liu, Y., Viergever, M. A., Jiang, T., and Dijkhuizen, R. M. (2011). Temporal scaling properties and spatial synchronization of spontaneous blood oxygenation level-dependent (BOLD) signal fluctuations in rat sensorimotor network at different levels of isoflurane anesthesia. NMR Biomed. 24, 61-67.

Williams, K. A., Magnuson, M., Majeed, W., Laconte, S. M., Peltier, S. J., Hu, X., and Keilholz, S. D. (2011). Comparison of alphachloralose, medetomidine and isoflurane anesthesia for functional connectivity mapping in the rat. Magn. Reson. Imaging 28, 995-1003.

Xerri, C., Stern, J. M., and Merzenich, M. M. (1994). Alterations of the cortical representation of the rat ventrum induced by nursing behavior. J. Neurosci. 14, 1710-1721.
Xi, Z. X., Wu, G., Stein, E. A., and Li, S. J. (2004). Opiate tolerance by heroin self-administration: an fMRI study in rat. Magn. Reson. Med. 52, 108-114.

Ye, Y., Zhuo, Y., Xue, R., and Zhou, X. J. (2011). BOLD fMRI using a modified HASTE sequence. Neuroimage 49, 457-466.

Yu, X., Wadghiri, Y. Z., Sanes, D. H., and Turnbull, D. H. (2005). In vivo auditory brain mapping in mice with Mn-enhanced MRI. Nat. Neurosci. 8, 961-968.

Zhang, N., Rane, P., Huang, W., Liang, Z., Kennedy, D., Frazier, J. A., and King, J. (2011). Mapping restingstate brain networks in conscious animals. J. Neurosci. Methods 189 , 186-196.

Conflict of Interest Statement: The author declares that the research was conducted in the absence of any commercial or financial relationships that could be construed as a potential conflict of interest.

Received: 17 March 2011; accepted: 29 June 2011; published online: 12 July 2011. Citation: Febo M (2011) Technical and conceptual considerations for performing and interpreting functional MRI studies in awake rats. Front. Psychiatry 2:43. doi: 10.3389/fpsyt.2011.00043

This article was submitted to Frontiers in Child and Neurodevelopmental Psychiatry, a specialty of Frontiers in Psychiatry. Copyright (c) 2011 Febo. This is an openaccess article subject to a non-exclusive license between the authors and Frontiers Media SA, which permits use, distribution and reproduction in other forums, provided the original authors and source are credited and other Frontiers conditions are complied with. 